\title{
Two-step evolution of auroral acceleration at substorm onset
}

\author{
A. Morioka, ${ }^{1}$ Y. Miyoshi, ${ }^{2}$ Y. Miyashita, ${ }^{2}$ Y. Kasaba, ${ }^{3}$ H. Misawa, ${ }^{1}$ F. Tsuchiya, ${ }^{1}$ \\ R. Kataoka, ${ }^{4}$ A. Kadokura, ${ }^{5}$ T. Mukai, ${ }^{6}$ K. Yumoto, ${ }^{7}$ D. J. Menietti, ${ }^{8}$ G. Parks, ${ }^{9}$ K. Liou, ${ }^{10}$ \\ F. Honary, ${ }^{11}$ and E. Donovan ${ }^{12}$
}

Received 16 February 2010; revised 1 June 2010; accepted 29 June 2010; published 19 November 2010.

[1] The sudden formation of parallel electric fields in the magnetosphere-ionosphere (M-I) coupling system is essential to complete substorm onset. From this standpoint, we focus substorm ignition on field-aligned acceleration by studying the dynamical behavior of auroral kilometric radiation. Field-aligned auroral acceleration shows a distinct two-step evolution at substorm onset: the activation of low-altitude acceleration $(\mathrm{h} \sim 4000-5000 \mathrm{~km})$ which corresponds to auroral initial brightening and the subsequent abrupt breakout of high-altitude acceleration ( $\mathrm{h} \sim 6000-12,000 \mathrm{~km}$ ) which corresponds to auroral breakup. Cases when only low-altitude acceleration (first-step evolution) is activated are pseudosubstorms. This indicates that the second evolution of field-aligned acceleration divides full substorm from pseudosubstorm. The statistical relationship between the plasma flow burst in the plasma sheet and its response to the M-I coupling region shows that about $65 \%$ of flow bursts cause pseudobreakup/initial brightening (low-altitude acceleration) and one third of them develops into full substorm (low-altitude and highaltitude accelerations), while the magnitude of flow velocity does not necessarily distinguish between pseudobreakup and full substorm. This suggests that some plasma flow bursts originate field-aligned current which first enhance low-altitude acceleration, and the increasing field-aligned current induces second acceleration above the preexisting low-altitude acceleration as a consequence of current/current-driven instabilities. In this sense, the substorm is finally ignited in the auroral M-I coupling region.

Citation: Morioka, A., et al. (2010), Two-step evolution of auroral acceleration at substorm onset, J. Geophys. Res., 115, A11213, doi:10.1029/2010JA015361.

\section{Introduction}

[2] Auroral substorm morphology documented by Akasofu [1964] has been widely accepted; the early expansion phase

\footnotetext{
${ }^{1}$ Planetary Plasma and Atmospheric Research Center, Tohoku University, Sendai, Japan.

${ }^{2}$ Solar-Terrestrial Environment Laboratory, Nagoya University, Nagoya, Japan.

${ }^{3}$ Geophysical Institute, Tohoku University, Sendai, Japan.

${ }^{4}$ Interactive Research Center, Tokyo Institute of Technology, Tokyo, Japan.

${ }^{5}$ National Institute of Polar Research, Tokyo, Japan.

${ }^{6}$ Japan Aerospace Exploration Agency, Tokyo, Japan.

${ }^{7}$ Space Environment Research Center, Kyushu University, Fukuoka, Japan.

${ }^{8}$ Department of Physics and Astronomy, University of Iowa, Iowa City, Iowa, USA.

${ }^{9}$ Space Sciences Laboratory, University of California, Berkeley, California, USA.

${ }^{10}$ Johns Hopkins University Applied Physics Laboratory, Laurel, Maryland, USA.

${ }^{11}$ Department of Communication Systems, Lancaster University, Lancaster, UK.

${ }^{12}$ Department of Physics and Astronomy, University of Calgary, Calgary, Alberta, Canada.

Copyright 2010 by the American Geophysical Union. 0148-0227/10/2010JA015361
}

of auroral substorms is characterized by sudden brightening of one of the quiet arcs or a sudden formation of an arc (Stage I of expansion phase) which is followed by rapid poleward motion of the brightened arc, resulting in an auroral bulge within a few minutes (Stage II of expansion phase). Stage I, which is not followed by Stage II, is called a "pseudobreakup". These two stages of auroral substorm onset imply that substorm onset is composed of a two-step auroral particle injection and/or an acceleration process. However, the physical process for the stepwise auroral development in the ionosphere and its relation to substorm triggering in the magnetosphere are still not fully understood.

[3] From this viewpoint, geophysical differences between pseudobreakups and full substorms have been studied. McPherron [1991] noted that pseudobreakups are characterized by short lifetimes, extreme localization, and weak magnetic perturbations on the ground. Many extensive studies have been carried out in the magnetosphere, and these have led to the conclusion that pseudobreakups do not show any distinct differences in plasma, particle, or field characteristics with those of full substorms, except for their magnitudes [Ohtani et al., 1993; Koskinen et al., 1993; Nakamura et al., 1994; Sergeev et al., 1995; Aikio et al., 1999; Partamies et al., 2003]. The association of Earthward flow bursts in the plasma sheet with pseudobreakups 
has also been reported by Nakamura et al. [2001a, 2001b]. The results obtained from these numerous studies have confirmed that there are no significant physical differences between pseudobreakups and full substorms in the magnetosphere and on the ground. Aikio et al. [1999] considered that there was a phenomenological continuum of states between small pseudobreakups and large substorms.

[4] Ieda et al. [2001] found that auroral brightening associated with reconnection does not always develop into global substorms and suggested that the formation of a nearEarth neutral line is not a sufficient condition to trigger a full substorm. Ohtani et al. [2002a] suggested that an unknown condition is necessary to develop from a pseudobreakup to a full substorm, even when magnetic flux transport is sufficient from the midtail region to the inner plasma sheet region.

[5] There are currently two major scenarios for the trigger of a substorm: the near-Earth neutral line model [e.g., Baker et al., 1996; Shiokawa et al., 1998a; Angelopoulos et al., 2008], which claims that magnetic reconnection in the midtail initiates substorm onset, and the current disruption model [e.g., Lui et al., 1992; Erickson et al., 2000; Lui et al., 2008], which claims that cross-tail current disruption in the near-Earth tail region triggers substorm onset. Both scenarios operate in the magnetosphere and are not necessarily self-evident with the auroral breakup process in the ionosphere, whereas the sudden formation of a parallel electric field in the magnetosphere-ionosphere (M-I) coupling region is essential to complete substorm onset.

[6] The auroral particle acceleration parallel to the ambient magnetic field in the upward field-aligned current (FAC) region was first found by sounding rocket observations [e.g., Evans, 1974; Arnoldy et al., 1974] and confirmed by satellite observations [e.g., Shelley et al., 1976; Mizera and Fennell, 1977]. Direct evidence of parallel electric fields in the auroral acceleration region was reported by Mozer et al. [1977]. Subsequently, many polar orbiting satellites have disclosed large-scale and small-scale structures of fieldaligned potential and their relation to auroral particle acceleration. Recent in situ observations from the Polar and Fast Auroral Snapshot (FAST) satellites revealed detailed characteristics of field-aligned electric fields together with accelerated particle spectra [e.g., McFadden et al., 1999a] and background plasma distributions therein [e.g., McFadden et al., 1999b]. These observations suggest that parallel electric fields are located at two altitudes (high altitude $\mathrm{E}_{/ /}$and low altitude $\mathrm{E}_{/ /}$) from about 0.5 to $2 R_{E}$ [Mozer and Kletzing, 1998; Mozer and Hull, 2001; Ergun et $a l ., 2002]$. These in situ observations greatly contributed to the understanding of the quasi-steady auroral particle acceleration.

[7] From the standpoint of abrupt particle precipitation at substorm onset, the next focus should be on the dynamical particle acceleration process in the M-I coupling region. Recently, Morioka et al. [2009] found that the field-aligned auroral acceleration shows two distinct types of evolution at substorm onset by studying the dynamical behavior of auroral kilometric radiation (AKR).

[8] AKR emanates from accelerated auroral electrons in the auroral plasma cavity, and the auroral electrons are accelerated in the field-aligned acceleration region formed in the auroral cavity, as has been confirmed by Viking
[Louarn et al., 1990] and FAST observations [Ergun et al., 1998; Strangeway et al., 2001; Pottelette et al., 2001]. Therefore, we can consider the source region of AKR to be almost identical to the auroral particle acceleration region, and AKR is the only auroral phenomenon that provides remote information on the vertical structure and dynamics of the acceleration region, although there remain some arguments that the free energy source of AKR is trapped electrons [Louarn et al., 1990; Pritchett et al., 1999]. The altitude range of the $\mathrm{AKR}$-source/acceleration region is estimated from AKR frequency taking into consideration that AKR emanates at a local electron cyclotron frequency in the source along the auroral field line [Pritchett et al., 1999, and 2002, and references therein]. The abrupt frequency expansion of AKR into both higher and lower frequencies at substorm onset is considered to be the development of the $\mathrm{AKR}$-source/acceleration region along the auroral magnetic field line [Kaiser and Alexander, 1977; Morioka et al., 1981; Liou et al., 2000; de Feraudy et al., 2001; Hanasz et al., 2001]. Fairfield et al. [1999] utilized AKR as the proxy of auroral particle acceleration to compare the magnetospheric phenomena with substorms. Morioka et al. [2007, 2008] showed that "high-altitude AKR" develops explosively (amplitude increases 10,000 times within $30 \mathrm{~s}$ ) at higher altitudes above a preexisting "low-altitude AKR source" at substorm onset. The breakup of this high-altitude AKR suggests the abrupt formation of a new field-aligned acceleration region above the low-altitude acceleration region.

[9] In this paper, we investigate the detailed evolution of two-step acceleration in the M-I coupling region at substorm. Then, we examine the relationship between the evolution of field-aligned acceleration and plasma flow bursts in the plasma sheet to comprehend the ignition of a substorm process taking place between the plasma sheet and the M-I coupling region.

\section{Data Sets and Terminology}

[10] Many simultaneous data sets are used to examine time-dependent substorm phenomena between the plasma sheet, the M-I coupling region, and the ground. The Polar/ Plasma Wave Instrument (PWI) database [Gurnett et al., 1995] provides high time resolution spectrograms of plasma waves with $2.3 \mathrm{~s}$ resolution observed in polar orbit with an apogee height of about $9 R_{E}$. Global UV auroral images are also provided from Polar/ultraviolet imager (UVI) observations [Torr et al., 1995] with a frame rate of roughly one or two frames a minute. We use images in wavelengths near $1700 \AA$ (longer wavelength band of Lyman-Birge-Hopfield emission) and $1500 \AA$ (shorter wavelength band of Lyman-Birge-Hopfield emission).

[11] The Geotail satellite was launched in 1992 into equatorial orbit. The apogee and perigee altitude of the spacecraft was 31 and $9 R_{E}$, respectively, since 1995 . Its database provides long-term data on plasma wave spectrograms with $8 \mathrm{~s}$ resolution (Geotail/PWI [Matsumoto et al., 1994]), electric field and magnetic field data with 3 s resolution (Geotail/electric field (EFD) [Tsuruda et al., 1994; Kokubun et al., 1994]), and ion moment data with $12 \mathrm{~s}$ resolution (Geotail/low-energy particle (LEP) [Mukai et al., 1994]) since 1992. The altitude-time $a$ - $t$ diagrams of AKR 
31 October 1997

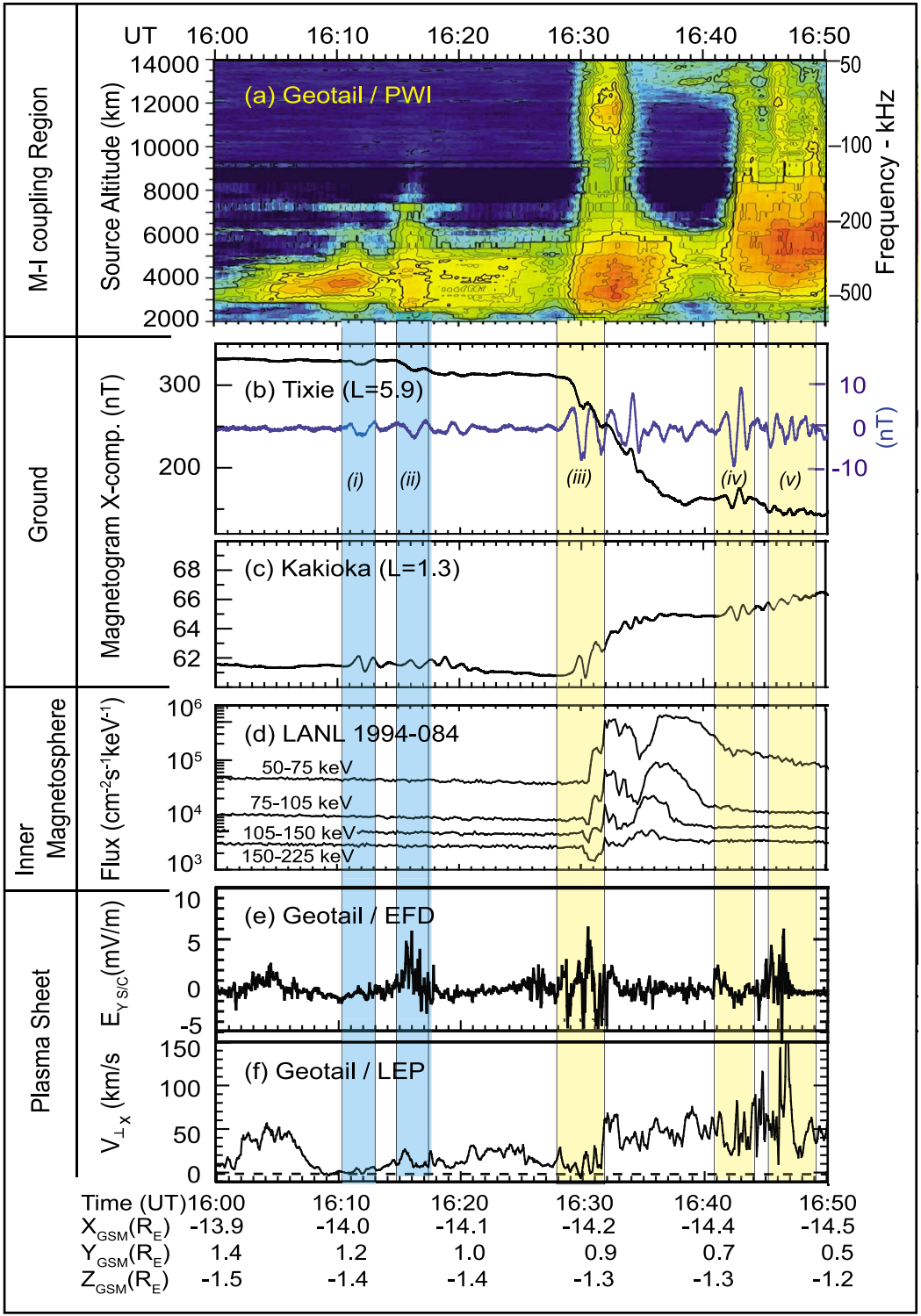

Figure 1. Overview of substorm phenomena on 31 October 1997. (a) Altitude-time (a- $t$ ) diagram of AKR source, which indicates the vertical evolution of field-aligned acceleration. Right ordinate indicates corresponding AKR frequency. Faint emissions in the altitude range from 12,500 to 14,000 km for 16361642 UT are not real AKR source region but are apparent ones resulting from natural LF emissions. (b) Magnetogram at Tixie $(L=5.9)$. Blue line indicates ULF component (right ordinate). (c) Magnetogram at Kakioka $(L=1.3)$. (d) Energetic electron fluxes at synchronous orbit (LANL satellite). (e) Electric field at Geotail in the midtail. (f) $X$ component velocity of plasma flow perpendicular to local magnetic field at Geotail.

(diagrams of time versus AKR source altitude along the field line of $L=7$ [see Morioka et al., 2008]) are derived from AKR spectra obtained by Geotail/PWI and Polar/PWI. The electric field data are calibrated by using in situ plasma data [Kasaba et al., 2006].

[12] The all-sky auroral TV movie data at Syowa Station (National Institute of Polar Research, Japan) are used to study the fine evolution of optical auroral substorms. The Meridian Photometer Array data from the Norstar/Canada facility [Donovan et al., 2003] are used to identify substorm phases.

[13] Substorm events are basically defined from ground geomagnetic field observations. Geomagnetic data with 1 or $5 \mathrm{~s}$ resolution at auroral latitudes, midlatitudes, and low-latitudes are available from well-maintained database systems: the World Data Center (WDC) for Aurora at the National Institute of Polar Research, Japan, the SubAuroral Magnetometer Network (SAMNET) at Lancaster 

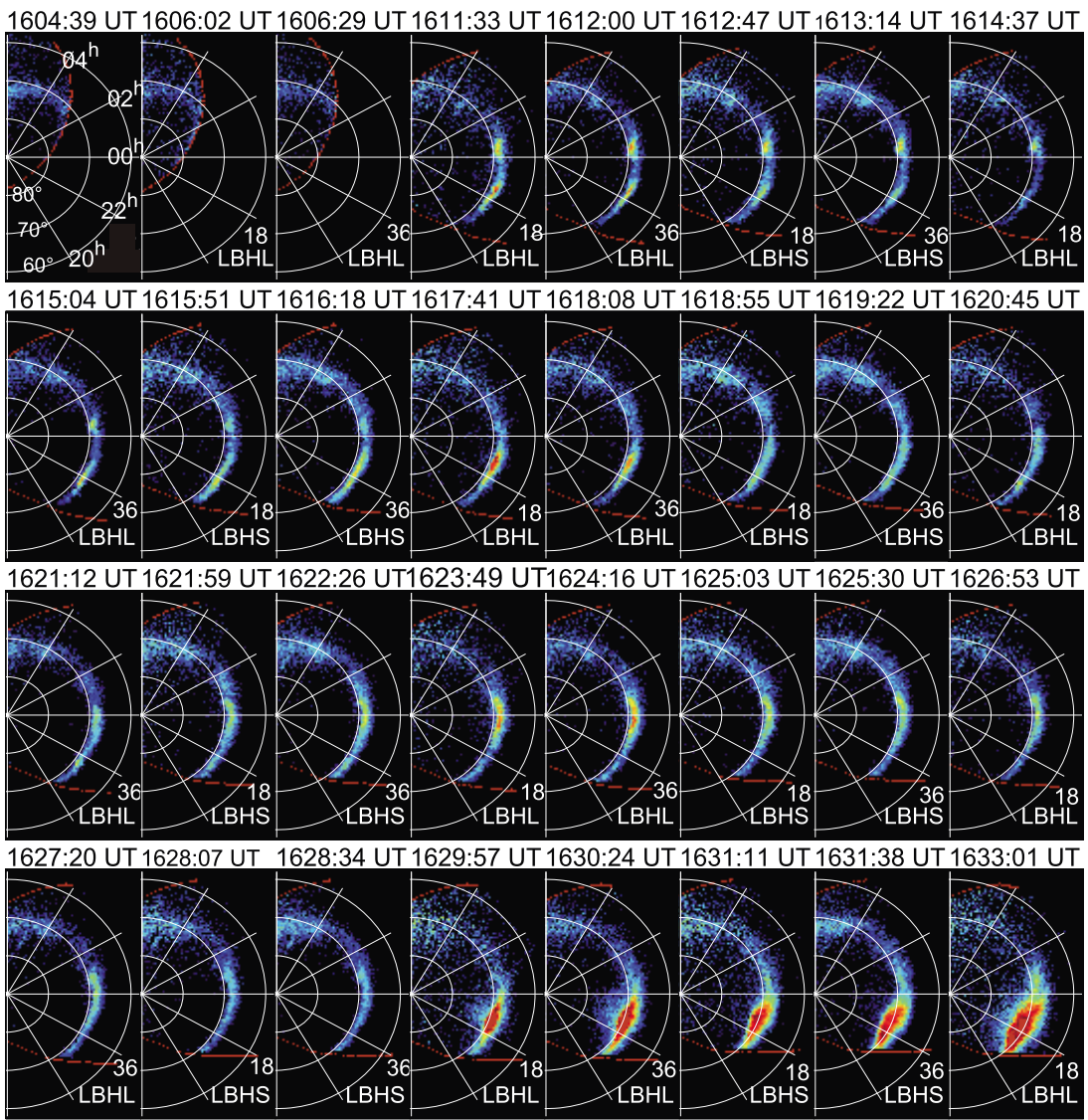

\section{Ultraviolet Imager/Polar}

Day (304) 31 Oct 1997

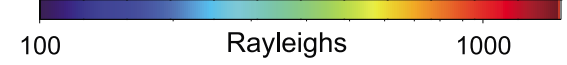

Figure 2. Auroral activity during the period of Figure 1 observed by Polar/UVI. Each frame indicates the northern dark hemisphere from $60^{\circ}$ to $90^{\circ}$ MLAT.

University, the Canadian Array for Realtime Investigations of Magnetic Activity (CARISMA) magnetometer network through the Canadian Space Science Data Portal [Mann et al., 2008], the $210^{\circ}$ Magnetic Meridian Chain at Kyushu University [Yumoto and $210^{\circ} \mathrm{MN}$ Magnetic Observation Group, 1996], and WDC-2 for Geomagnetism at Kyoto University.

[14] Here, we will define the technical terms, full substorm and pseudosubstorm, used in this paper. Auroral substorms that begin with initial brightening and are accompanied by longitudinal and poleward expansion are designated "full substorms", and those that stay in an initially activated area followed by no global developments are called "pseudosubstorms", according to Ohtani et al. [1993].

\section{Overview of Field-Aligned Acceleration at Substorm Onset}

[15] Figure 1 overviews the development of small and large substorms on 31 October 1997, showing an $a-t$ diagram of the AKR source derived from Geotail/PWI (Figure 1a), magnetograms on the ground (Figures $1 \mathrm{~b}$ and 1c), electron fluxes in synchronous orbit from the Los Alamos National Laboratory (LANL) satellite (Figure 1d), and the dawn-dusk electric field (Figure 1e) and X com- ponent plasma flow velocity (Figure 1f) in the plasma sheet observed by Geotail. As the source altitude of AKR is considered to be almost identical with that of the fieldaligned auroral acceleration region, as mentioned in the section 1 , the $a-t$ diagram of the AKR source will be, hereafter, regarded as a manifestation of the dynamical behavior of the auroral acceleration. Thus, Figure 1a represents the development of auroral acceleration regions in the M-I coupling region. Magnetospheric activity was expected to become active: the $B_{z}$ component of the interplanetary magnetic field (IMF; from the OMNI-2 data) had changed to negative at 1515 UT and was keeping a value of around $-2.5 \mathrm{nT}$ during the period in Figure 1 (not shown). [16] A low-altitude acceleration region [Morioka et al., 2007] appeared in an altitude range from $3000-5000 \mathrm{~km}$ at the beginning of the $a-t$ diagram. This low-altitude acceleration is considered to correspond to so-called inverted-V acceleration [Morioka et al., 2007]. The acceleration gradually enhanced in intensity and slightly expanded in altitude toward higher and lower altitudes twice at about 1611 and 1616 UT (vertical blue rectangles (i) and (ii) in Figure 1). The moderate activation of these low-altitude accelerations in the M-I coupling region was accompanied by two low-latitude Pi2 pulsations on the ground (Kakioka Magnetic Observatory; $L=1.3$, midnight (magnetic local time $(\mathrm{MLT}))=1504 \mathrm{UT})$, as shown in Figure 1c. The 

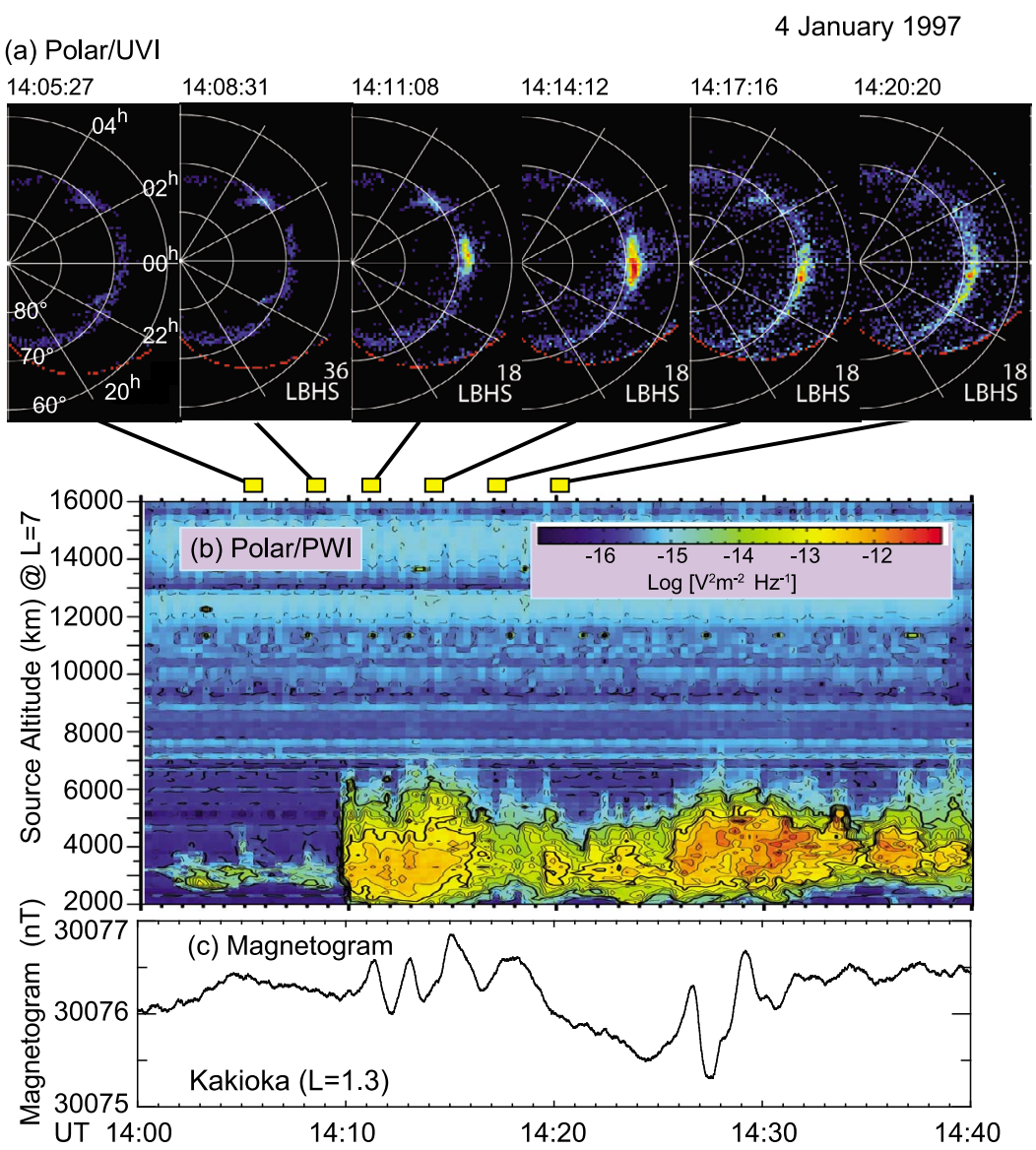

Figure 3. Pseudobreakup and field-aligned acceleration on 4 January 1997. (a) Polar/UVI images. Each frame indicates the northern dark hemisphere from $60^{\circ}$ to $90^{\circ}$ MLAT. (b) An $a-t$ diagram of AKR source indicating the evolution of field-aligned acceleration. (c) Magnetogram at Kakioka $(L=1.3)$.

high-latitude magnetogram at Tixie $(L=6.1$, midnight $(\mathrm{MLT})=1604 \mathrm{UT})$ (Figure $1 \mathrm{~b})$ also showed small negative bays (black trace) and related $\mathrm{Pi} 2$ pulsations (blue trace) during the two periods of interest. These geomagnetic small disturbances on the ground and the intensification of the low-altitude acceleration in the M-I coupling region were corresponded to auroral pseudosubstorms. Figure 2 shows the UVI images from the Polar satellite. The field of view of UVI was turned to midnight after $1611 \mathrm{UT}$, and the imager began to picture two auroral pseudosubstorms after 1611:33 UT (from the fourth frame of the first row of Figure 2). One was located in the postmidnight region around 0.5 MLT showing gradual decrease in intensity and faded out at around 1615 UT. This auroral pseudosubstorm would correspond to the first activation of the low-altitude acceleration and related magnetic disturbances (rectangle (i) in Figure 1). The other auroral pseudosubstorm was centered on around 22 MLT. The intensification of this aurora at 1615:04 may correspond to the second activation of the low-altitude acceleration. The first issue to be addressed in this overview is that the activation of low-altitude acceleration in the M-I coupling region may cause an auroral intensification at pseudosubstorms.

[17] Major magnetic substorm onset can be defined between 1628 and 1632 UT (vertical yellow rectangle (iii) in Figure 1) from the sharp negative bay and $\mathrm{Pi} 2$ pulsation in the night-side high-latitude magnetogram at Tixie (Figure 1b) and from the positive bay accompanied by the low-latitude Pi2 pulsation at Kakioka (Figure 1c). The UV image data from the Polar satellite indicated an auroral breakup between 1628:34 and 1629:57 UT, as seen in Figure 2. The electron flux at synchronous orbit (1994-084 satellite; midnight $(\mathrm{MLT})=1652$ UT) showed a typical dispersionless injection almost simultaneously with the onset of the magnetic substorm (Figure 1d). Looking at the M-I coupling region (Figure 1a), the "high-altitude acceleration" broke out abruptly (AKR breakup [Morioka et al., 2008]) in the higher altitude range from 8000 to $14,000 \mathrm{~km}$, almost simultaneously with the onset of the major magnetic substorm. It is evident from the intensity contour of the $a-t$ diagram that this high-altitude acceleration region was not a simple extension from the preexisting low-altitude region but one that was newly created above the low-altitude acceleration. Here, note that AKR observations cannot assure that the low-altitude and high-altitude acceleration regions are on the same field line, because AKR has no information on its horizontal extent. However, on the basis of the intimate relations between low-altitude and high-altitude acceleration regions, as will be disclosed later, it is plausible that both acceleration regions are considered to be on the same field line, at least at the onset of a substorm.

[18] The $a-t$ diagram also showed that the breakout of high-altitude acceleration was preceded by about 1-2 min by the gradual activation of low-altitude acceleration, which 


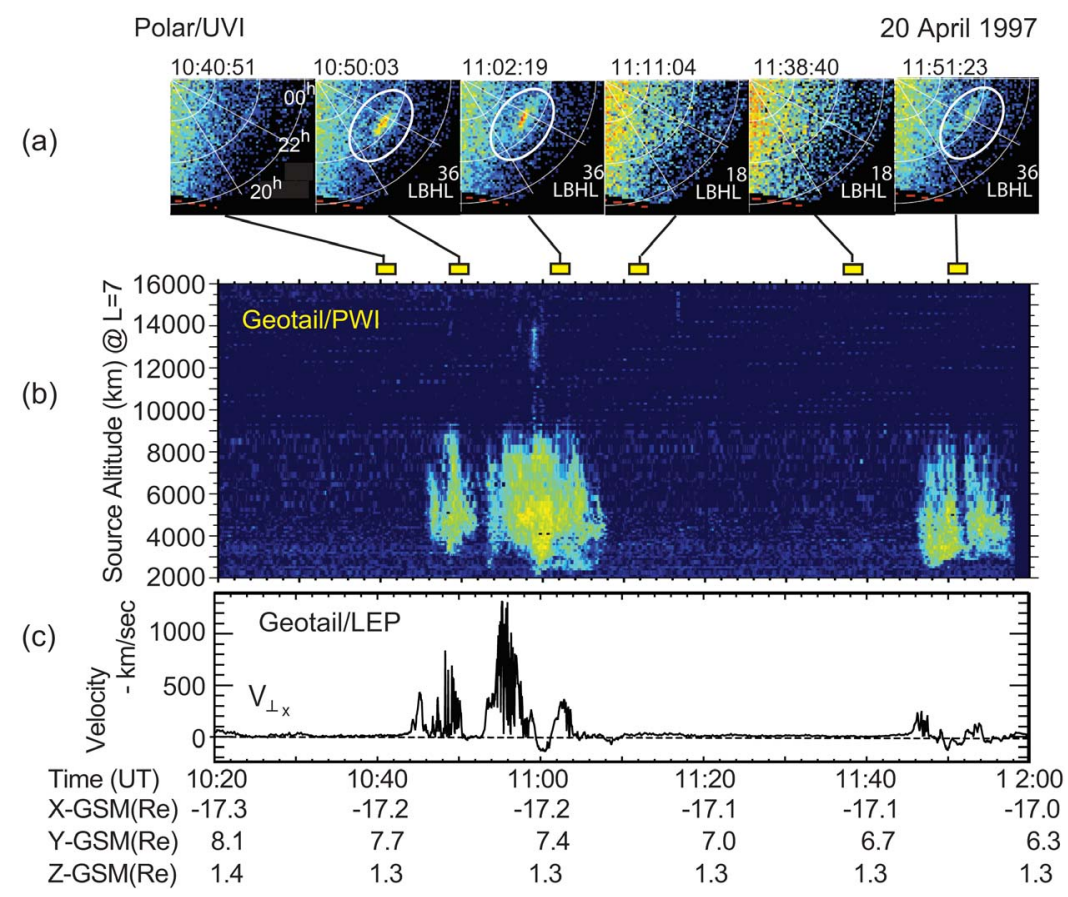

Figure 4. Quiet time pseudobreakup and related field-aligned acceleration on 20 April 1997. (a) Polar/ UVI images. The circles indicate the auroral pseudosubstorm. (b) An $a$ - $t$ diagram of AKR source. (c) $X$ component velocity of plasma flow perpendicular to local magnetic field at Geotail.

was slightly expanding toward higher and lower altitudes. The second issue to be addressed in this overview is that substorm onset is composed of the "two-step" evolution of field-aligned acceleration: the gradual intensification of low-altitude acceleration and the following abrupt breakout of high-altitude acceleration. It is also noteworthy that the manner in which the low-altitude acceleration increases in intensity and expands altitude around substorm onset is somewhat similar to that around pseudosubstorms at 1611 and 1616 UT. This suggests that the pseudosubstorm and the first stage of the full substorm result from the same activation process of low-altitude acceleration.

[19] The high-altitude acceleration region ceased once after a 5 min duration and broke out again at around 1641 and $1646 \mathrm{UT}$, corresponding to the second and third Pi2 pulsations at Tixie and Kakioka (two vertical yellow rectangles (iv) and (v)). Note that faint emissions in the $a-t$ diagram in the altitude range from 12,500 to $14,000 \mathrm{~km}$ for 1636-1642 UT are not a real AKR emission but an apparent one imaged by natural LF emissions.

[20] The two types of field-aligned acceleration (lowaltitude and high-altitude acceleration) as derived from the above AKR remote observations would correspond to the live features of statistically observed high-altitude and lowaltitude $E_{/ /}$from the in situ measurements by the Polar [Mozer and Hull, 2001] and FAST [Ergun et al., 2002] satellites. The low-altitude acceleration region would be the well-known inverted-V acceleration, which is commonly observed not only at substorm onset but also during the active period over the auroral oval, while high-altitude acceleration is characterized by the transient appearance only at substorm onset [Olsson et al., 2004; Morioka et al., 2007].
[21] During the periods of interest in Figure 1, the dawndusk electric field $E_{y S C}$ measured in the spacecraft coordinates (which is roughly equivalent to $E_{y \mathrm{GSE}}$ in the GSE coordinates) and plasma velocity $V_{\perp} x$ in the plasma sheet (Figures 1e and 1f) showed moderate Earthward plasma flow events ( $V_{\perp} x$ is the $X$ component velocity of perpendicular plasma flow to the local magnetic field). This suggests that Earthward plasma flows are strongly related to auroral acceleration in the M-I coupling region inducing pseudosubstorms or full substorms, as pointed out by Fairfield et al. [1999]. The third issue to be addressed in this overview is the investigation into the detailed relationship between the flow bursts in the plasma sheet and the fieldaligned acceleration in the M-I coupling region, which might provide important information on the substorm onset process.

[22] In the following, we examine the three issues previously pointed out: (1) activation of the low-altitude acceleration region and its relation to pseudosubstorms in section 4, (2) two-step evolution of the field-aligned acceleration and its relation to full substorms in section 5, and (3) causality between the plasma dynamics in the plasma sheet and the formation of field-aligned acceleration in the M-I coupling region in section 6 .

\section{Activation of Low-Altitude Acceleration and Pseudosubstorms}

\subsection{Quiet Time Pseudosubstorms and Low-Altitude Acceleration}

[23] Figure 3 shows a typical example of correspondence between pseudosubstorm and low-altitude acceleration on 4 January 1997. A pseudosubstorm is basically defined from 


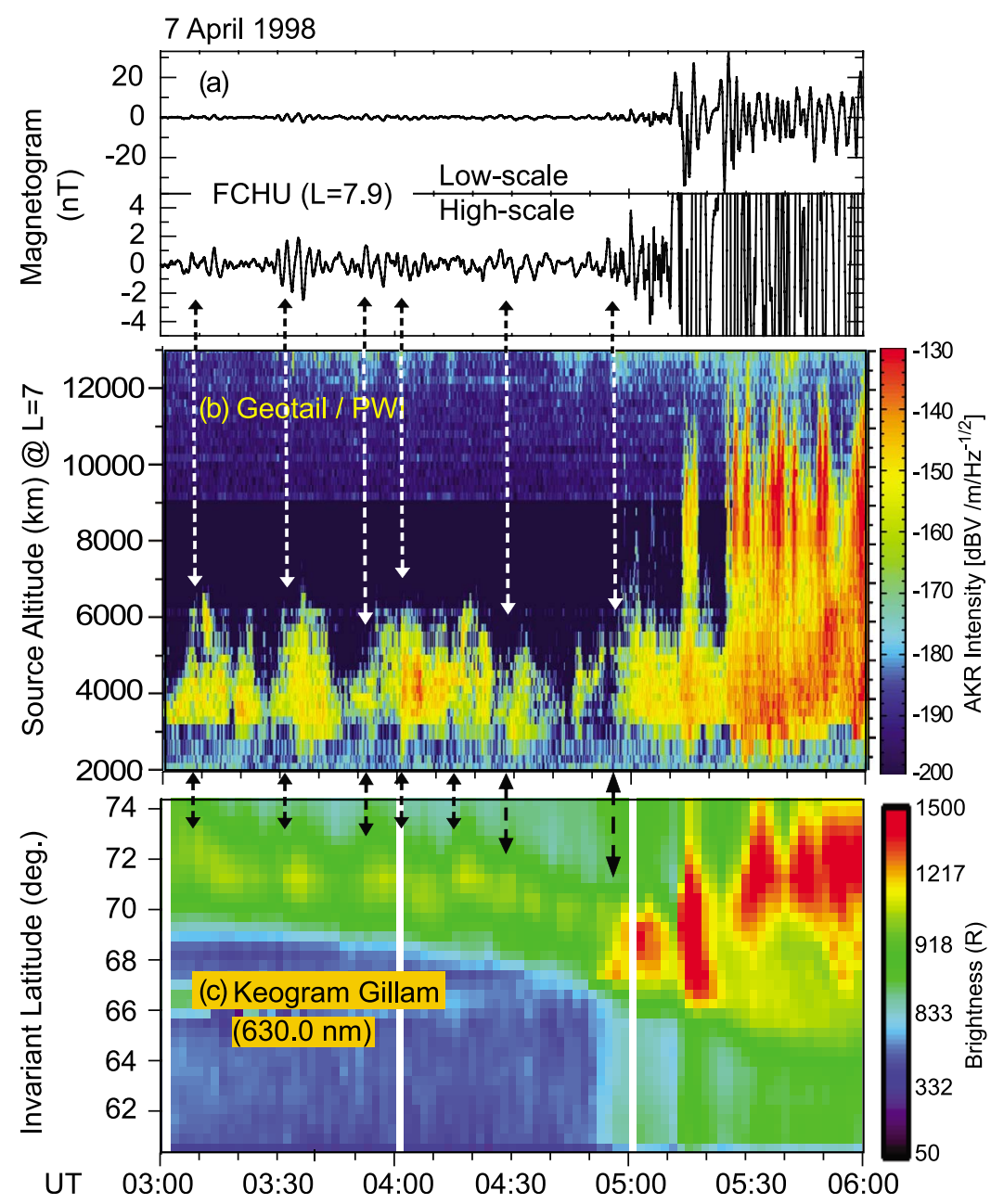

Figure 5. Auroral arc dynamics and field-aligned acceleration during the growth and expansion phase on 7 April 1998. (a) Magnetogram at FCHU $(L=7.9)$. Both the low-scale and high-scale data are shown. (b) An $a-t$ diagram of AKR source indicating the evolution of field-aligned acceleration. (c) Keogram of auroral red line $(6300 \mathrm{~nm})$ observed at Gillam $(L=6.5)$. Vertical broken lines indicate the correspondence between AKR intensifications, auroral modulations and Pi2 pulsations.

auroral images. The UV images (Figure 3a) showed a spotlike aurora of short duration $(\sim 10 \mathrm{~min})$ in the midnight region starting at around 1410 UT (third frame of Figure $3 a)$, which is categorized as an auroral pseudosubstorm. Concurrent with this auroral pseudosubstorm, the $a-t$ diagram (Figure 3b) derived from the Polar/PWI observation shows the appearance of low-altitude acceleration at about 1410 UT in an altitude range from $2000-6000 \mathrm{~km}$. This acceleration gradually decreased after 1416 UT, accompanying the fadeout of the auroral pseudosubstorm. The $a-t$ diagram again shows the activation of low-altitude acceleration at about 1426 UT. Corresponding to this second enhancement in the low-altitude acceleration region, an auroral spot appeared in the postmidnight oval (not shown). These activations were accompanied with two low-latitude Pi2 pulsations, as seen in the ordinary magnetogram (Figure $3 c$ ) at the low-latitude midnight station (Kakioka). Note that the ordinary magnetogram at Kakioka showed very small positive bays with comparable amplitudes with the simultaneous Pi2 pulsations $(\sim 1 \mathrm{nT})$. The period of interest was magnetically quiet (IMF $B_{z}$ component was weakly positive and $K p$ index was $0_{+}$). The pseudosubstorms shown here would belong to the "quiet time pseudobreakup" [Kullen and Karlsson, 2004].

[24] The intimate relationship between the auroral pseudosubstorm and low-altitude acceleration can be understood as an enhanced field-aligned electric field at low-altitude causing an auroral pseudosubstorm. A similar example of quiet time pseudobreakup is given in Figure 4, to further confirm the relation. Figures $4 \mathrm{a}$ and $4 \mathrm{~b}$ indicate that enhanced low-altitude field-aligned acceleration was accompanied by weak auroral intensifications (pseudobreakups) around 1046, 1054, and 1146 UT on 20 April 1997.

\subsection{Growth-Phase Pseudosubstorm and Low-Altitude Acceleration}

[25] Figure 5 shows the growth and expansion phase of an auroral substorm on 7 April 1998 with magnetograms at Fort Churchill $(\mathrm{FCHU})(L=7.9$, midnight $(\mathrm{MLT})=0635 \mathrm{UT})$ 

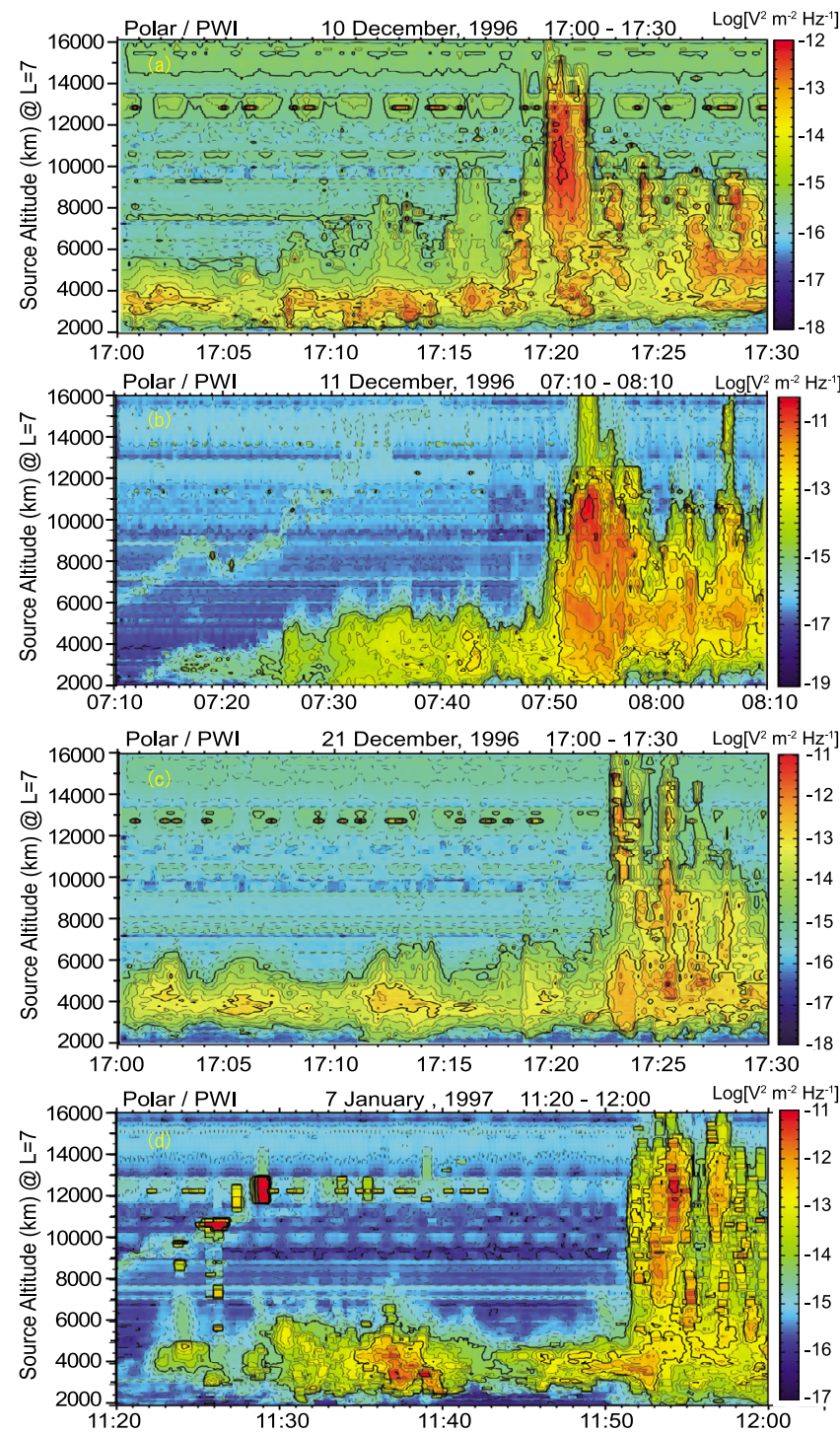

Figure 6. Examples of repeated pseudosubstorms during growth phase and final full substorm. Periodic structures at around $13,000 \mathrm{~km}$ are instrumental interference artifacts.

in Figure 5a, a $3 \mathrm{~h} a$ - $t$ diagram obtained from the Geotail/PWI in Figure $5 \mathrm{~b}$, and a keogram of auroral redline emission $(630 \mathrm{~nm})$ at Gillam $(L=6.6$, midnight $(\mathrm{MLT})=0637 \mathrm{UT})$ in Figure 5c. The keogram shows substorm growth phase with the gradual and continuous equatorward motion of the oval from $72^{\circ}\left(0300\right.$ UT) to $68^{\circ}(\sim 0512$ UT) and several auroral breakups at and after 0512 UT with sudden intensifications and poleward expansions of the auroral arc. The low-altitude acceleration, which had appeared at 0300 UT in the altitude of about $4000 \mathrm{~km}$ (Figure 5b), showed intensity modulations during the growth phase. It should be noted that the intensity modulations closely corresponded with frequent intensifications of the growth phase auroral oval seen in Figure 5c. The vertical lines in Figure 5c indicate the correspondence between the auroral intensifications, the acceleration enhancements, and the Pi2 pulsations (the pulsation data are shown by two different scales in Figure 5a). Six correspondences, at least, can be found during the growth phase, indicating that the enhanced low-altitude acceleration caused the pseudosubstorm. The pseudobreakup occurring at around 0455 was the largest one. These auroral intensifications during the growth phase are the growth phase pseudobreakups [Kullen and Karlsson, 2004]. The first auroral breakup was trigged at 0512 UT simultaneously with the breakout of high-altitude acceleration, and then, subsequently, three auroral intensifications occurred in the auroral bulge.

[26] A series of enhancements in low-altitude acceleration are sometimes observed preceding distinct substorm onset, as shown in Figure 6, in which repeated pseudosubstorms finally developed into a full substorm. It is suggested from these examples that substorm growth phase is composed of

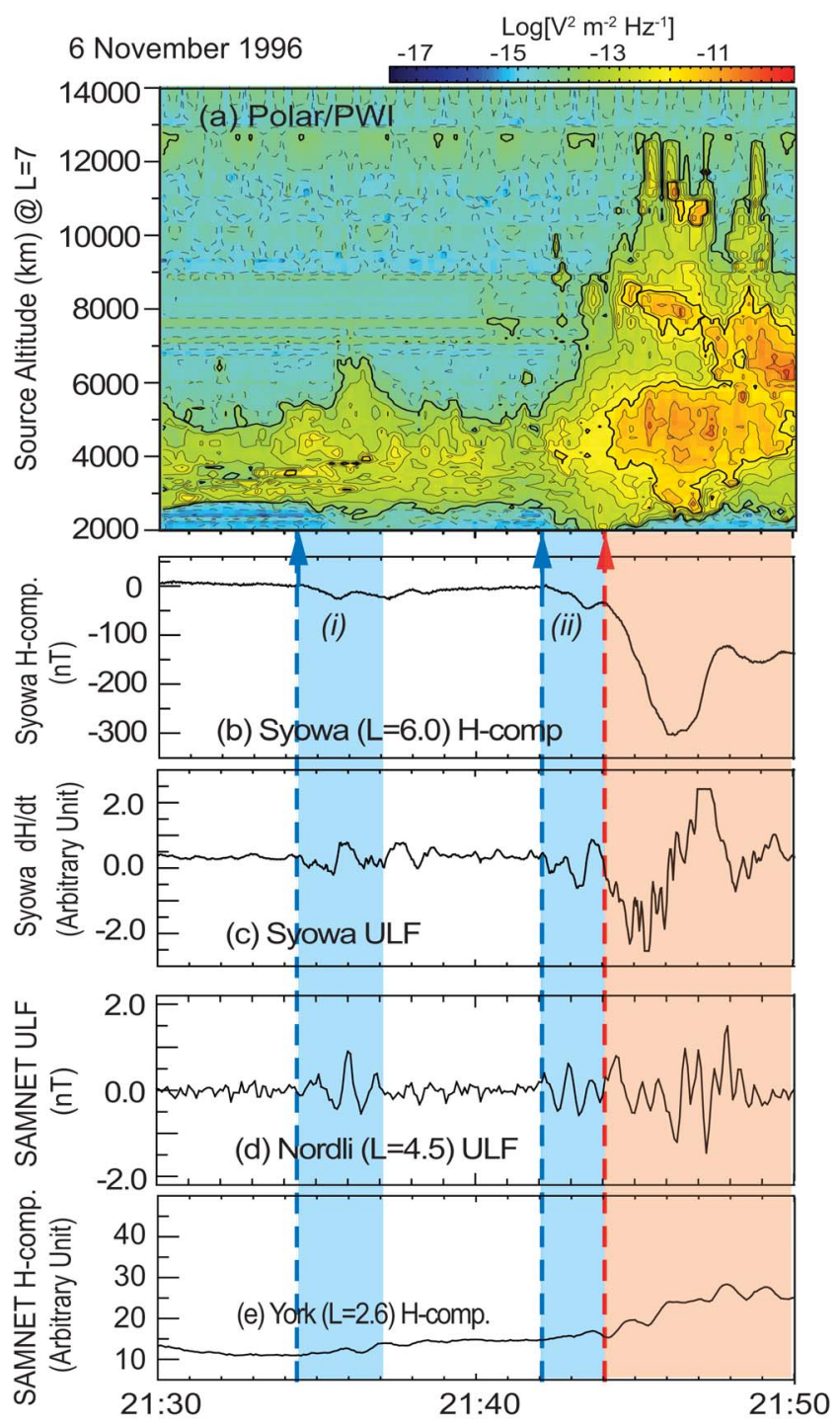

Figure 7. Pseudosubstorm and full-full substorm on 6 November 1996. (a) An $a-t$ diagram of AKR source indicating the evolution of field-aligned acceleration. (b) High-latitude magnetogram at Syowa $(L=6.0)$. (c) High-latitude ULF waves at Syowa. (d) Midlatitude ULF waves at Nordli $(L=4.5)$. (e) Midlatitude magnetogram at York $(L=2.6)$. 


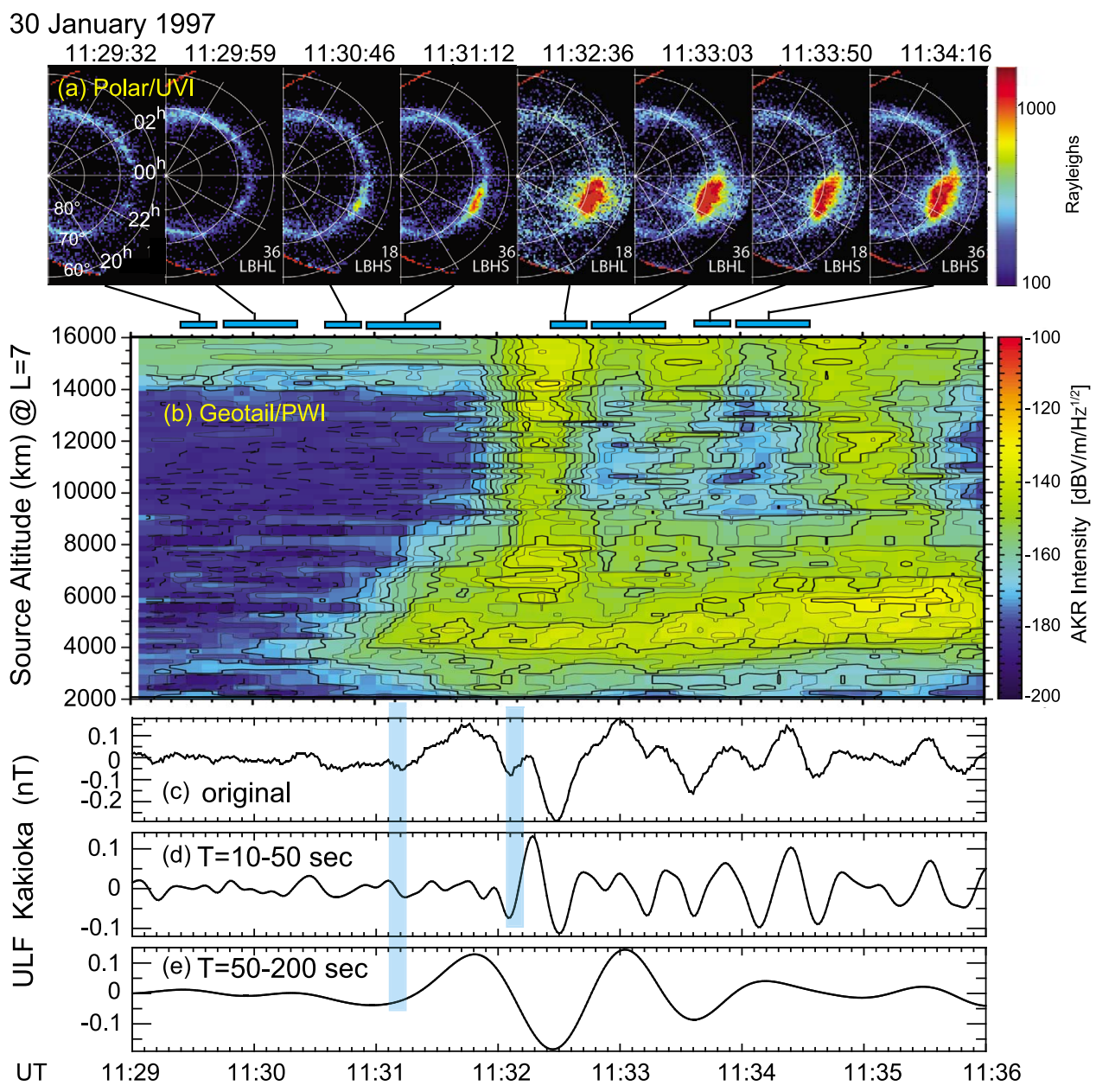

Figure 8. Two-step evolution of substorm onset. (a) Polar/UVI images. Each frame indicates the northern dark hemisphere from $60^{\circ}$ to $90^{\circ}$ MLAT. (b) An $a$ - $t$ diagram of AKR source indicating the evolution of field-aligned acceleration. Faint emissions above 14,000 km altitude are not real AKR source region but are apparent ones resulting from natural LF emissions. (c) Low-latitude ULF waves at Kakioka $(L=$ 1.3). (d) Short period component of Pi (breakup Pi). (e) Long period component of Pi pulsation (prebreakup Pi). Vertical blue bars correspond to onset of longer-period Pi and shorter-period Pi.

frequent low-altitude acceleration activations and pseudosubstorms in the M-I coupling region.

\section{Two-Step Evolution of Substorm Onset}

\subsection{Case Studies}

\subsubsection{Pseudosubstorm and Full Substorm on 6 November 1996}

[27] The blue rectangle (i) in Figure 7 indicates the period of enhanced low-altitude acceleration started from 2134 UT, with a central altitude of about $4000 \mathrm{~km}$, expanding to higher altitudes up to about $6000 \mathrm{~km}$. This enhancement is regarded as a pseudosubstorm. During the period depicted by this blue rectangle (i), the magnetogram at the night-side auroral station (Syowa; L $=6.0$, midnight $(\mathrm{MLT})=0006$ UT) showed a small negative bay (Figure 7b) and highlatitude $\mathrm{Pi} 2$ pulsation (Figure $7 \mathrm{c}$ ). The midlatitude magnetogram also showed a Pi2 pulsation at Nordli $(L=4.5$, midnight $(\mathrm{MLT})=1913 \mathrm{UT})($ Figure $7 \mathrm{~d})$ and a small pos- itive bay at York $(L=2.6$, midnight $($ MLT $)=2308$ UT $)$ (Figure 7e). These are typical features of ground pseudosubstorms [McPherron, 1991]. The second enhancement in the low-altitude acceleration began from 2142 UT, as indicated by the blue rectangle (ii). This acceleration gradually intensified in both magnitude and altitude range. The magnetic variations in the auroral-latitude and midlatitude stations during the period depicted by blue rectangle (ii) are quite similar to those in the previous pseudosubstorm in rectangle (i). During the course of this intensification, highaltitude acceleration (AKR breakup) suddenly appeared at about 2144 UT at an altitude from 7000-13,000 km. The sequence of these acceleration processes is the two-step evolution of field-aligned acceleration. The magnetograms from both the auroral-latitude and midlatitude stations showed a typical magnetic substorm as seen during the period of the red rectangle. These observations indicate that the first step of the two-step onset (period of rectangle (ii)) 


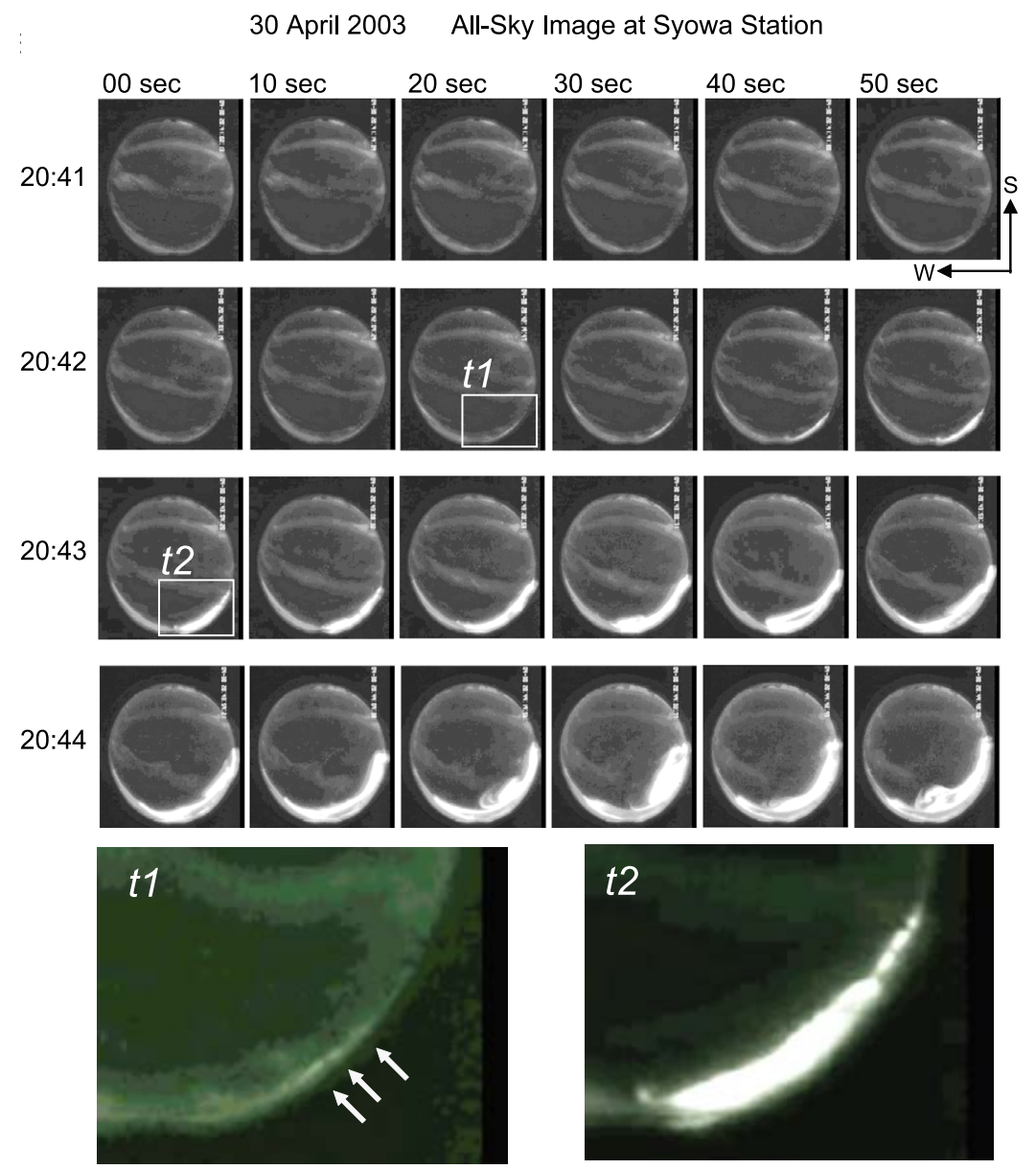

Figure 9. Fine evolution of auroral substorm on 30 April 2003. All $10 \mathrm{~s}$ frames from 2041 to $2044 \mathrm{UT}$ from all-sky imager at Syowa (Antarctica, $L=6.0$ ) have been shown. Frames $t 1$ (2042:20 UT) and $t 2$ (2043:00 UT) correspond to initial brightening and breakup, respectively. Bottom two frames are the enlargements of those at $t 1$ and $t 2$. Arrows in $t 1$ panel indicate elements of undulations.

is physically the same process as that of the pseudosubstorm (rectangle (i)).

\subsubsection{Full Substorm With Two-Step Pi Pulsations on 30 January 1997}

[28] Figure 8 shows the correspondence between the twostep evolution of field-aligned acceleration and the two separated irregular pulsations (Pi). Figure 8a indicates that initial brightening began between 1129:59 and 1130:46 UT, and auroral breakup with almost simultaneous poleward expansion broke out between 1131:12 and 1132:36 UT. Corresponding to these two typical signatures of auroral substorm, the $a-t$ diagram of AKR (Figure $8 \mathrm{~b}$ ) reveals enhanced low-altitude acceleration at around 1131 UT and the breakout of high-altitude acceleration at around 1132 UT: that is, the two-step evolution of field-aligned acceleration. Around the onset of this substorm, the low-latitude pulsation at Kakioka (Figure 8c) indicates the superposition of two component irregular pulsations. Figures $8 \mathrm{~d}$ and $8 \mathrm{e}$ show the shorter-period and longer-period components of the $\mathrm{Pi}$ pulsation based on the Hilbert-Huang transform [Kataoka et al., 2009]. The two component waves were different in their start time: the irregular pulsation with a longer period from 50-200 s started concurrently with the enhanced low-altitude acceleration (hereafter termed prebreakup irregular pulsation (prebreakup Pi)), and the pulsation with a shorter period from 10-50 s (hereafter termed breakup $\mathrm{Pi}$ ) was triggered at the onset of high-altitude acceleration. These are consistent with the earlier analyses of geomagnetic pulsations at substorm onset by Morioka et al. [2009] and Kataoka et al. [2009].

5.1.3. Fine Evolution of Full Substorm on 30 April 2003

[29] The event in Figures 9 and 10 demonstrates auroral fine development that followed the two-step evolution of field-aligned acceleration. Figure 9 shows all-sky auroral images from the Syowa station (Antarctica) from 2041:00 to 2044:50 UT every $10 \mathrm{~s}$ on 30 April 2003. The most equatorward arc had been stable until 2042:10 UT. At 2042:20 UT, the southeastern part of the arc began to intensify, forming a dotted structure in the longitudinal direction $(t 1$ : the enlarged frame of the arc is at the bottom left). This intensification preceding auroral breakup would be identical with the recent reports on prebreakup auroral activity taken from the all-sky imager of the Time History of Events and Macroscale Interactions during Substorms (THEMIS) mission. Donovan et al. [2006] reported the azimuthal evolution of an auroral arc around substorm onset. Liang et al. [2008] 


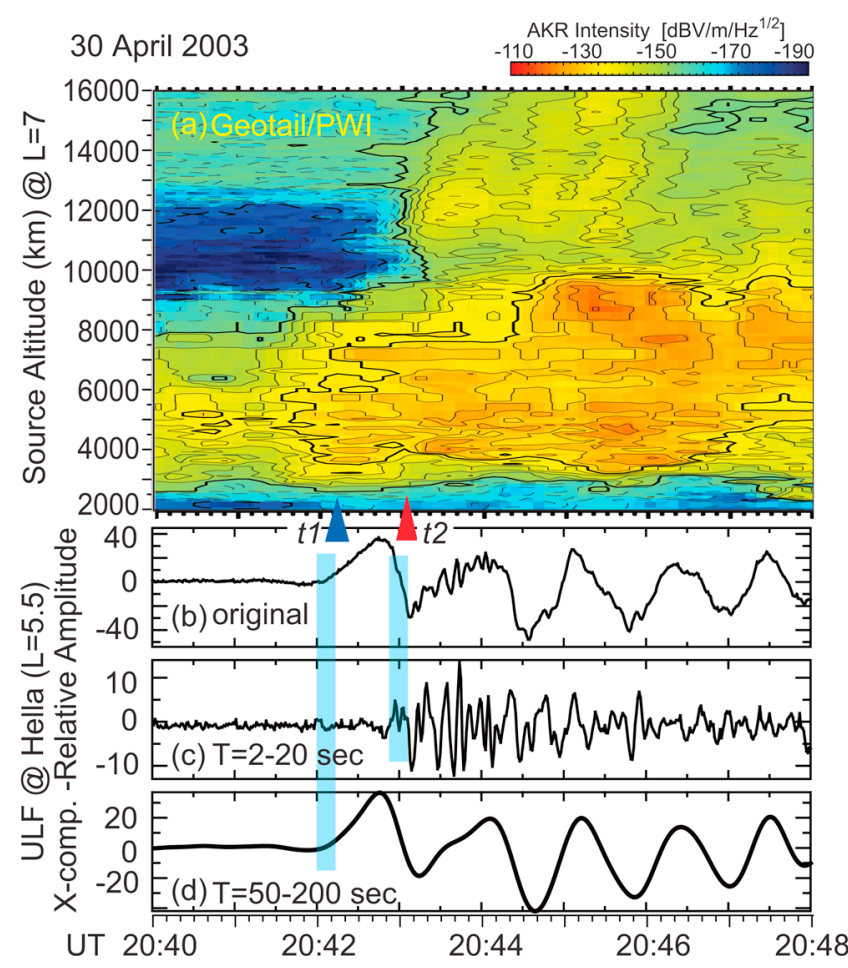

Figure 10. Evolution of field-aligned acceleration and $\mathrm{Pi}$ pulsation at substorm onset on 30 April 2003. (a) An $a-t$ diagram of AKR source indicating two-step evolution of fieldaligned acceleration. (b) Midlatitude ULF waves at Hella $(L=5.5)$. (c and d) Short-period and long-period components of Pi pulsation respectively. Triangles $t 1$ and $t 2$ correspond to initial brightening and breakup in Figure 9. Vertical blue bars correspond to onset of longer-period Pi and shorter-period Pi. noticed a wavy formation in a prebreakup arc. Rae et al. [2009] pointed out small-scale optical undulation along the most equatorward preexisting auroral arc prior to auroral breakup. The dotted structure of the present arc at $t 1$ in Figure 9 grew gradually, and it suddenly intensified with poleward expansion at 2043:00 UT ( $t 2$ : the enlarged frame of the arc is at the bottom right). After that, the auroral substorm expanded to a full substorm. Figure 10 shows the corresponding $a-t$ diagram of the AKR source from Geotail/ PWI (Figure 10a) and $\mathrm{Pi}$ at the Hella Station $(L=5.5$, midnight $($ MLT) $=0009$ UT) (Figures 10b-10d). The blue and red triangles in Figure 10a correspond to the time of arc intensification with dotted structure $(t 1)$ and the sudden intensification with poleward expansion $(t 2)$ defined in Figure 9. It is evident that these auroral epoch times correspond to the enhanced low-altitude acceleration at $t 1$ and to the breakout of high-altitude acceleration at $t 2$. The simultaneous Pi again showed that it involves two separated wave trains; that is, prebreakup Pi with a period from 50 to $200 \mathrm{~s}$ triggered at enhanced low-altitude acceleration and breakup Pi with a period from 2 to $20 \mathrm{~s}$ concurrent with the breakout of high-altitude acceleration, as indicated by the thick blue vertical lines.

\subsection{Relationship Between AKR Type and Auroral Type at Substorm Onset}

[30] Within the context where the two-step evolution of field-aligned acceleration divides a full substorm from a pseudosubstorm, it is expected that AKR breakup would always accompany a full substorm and AKR, which is intensified only in low-altitude, would always accompany a pseudosubstorm. To investigate this presumption, AKR events (from Geotail/PWI data) associated with isolated auroral intensification (from Polar/UVI data) were systematically surveyed for the period from December 1996 to February 1997. Pi2 observations at Kakioka were used to

Table 1. Correspondence Between AKR and Auroral Types at Substorm Onset ${ }^{\mathrm{a}}$

\begin{tabular}{|c|c|c|c|c|c|c|c|}
\hline \multirow[b]{2}{*}{ Date $^{b}$} & \multirow[b]{2}{*}{ Pi2 Onset (UT) } & \multicolumn{2}{|c|}{$\mathrm{AKR}$} & \multicolumn{4}{|c|}{ UV Aurora } \\
\hline & & Onset (UT) & Type & Onset (UT) & Type & MLT (hr) & MLAT (deg) \\
\hline $96 / 12 / 05$ & 1517 & 1517 & $\mathrm{~L}$ & $1516: 47 \pm 37$ & PSD & 23 & 70 \\
\hline $96 / 12 / 06$ & 1316 & 1316 & $\mathrm{~L}$ & $1314: 31 \pm 18$ & PSD & 23 & 72 \\
\hline $96 / 12 / 09$ & 1430 & 1430 & $\mathrm{H} / \mathrm{L}$ & $1429: 58 \pm 37$ & Full & 22.5 & 70 \\
\hline $97 / 01 / 02$ & 1255 & 1255 & $\mathrm{H} / \mathrm{L}$ & $1255: 00 \pm 37$ & Full & 23 & 70 \\
\hline $97 / 01 / 02$ & 1402 & 1401 & $\mathrm{H} / \mathrm{L}$ & $1359: 24 \pm 37$ & Full & 0.5 & 70 \\
\hline $97 / 01 / 02$ & 1506 & 1507 & $\mathrm{H} / \mathrm{L}$ & $1505: 21 \pm 19$ & Full & 0 & 69 \\
\hline $97 / 01 / 05$ & 1326 & 1327 & $\mathrm{~L}$ & $1326: 00 \pm 37$ & PSD & 23 & 68 \\
\hline $97 / 01 / 13$ & 1250 & 1250 & $\mathrm{H} / \mathrm{L}$ & $1250: 39 \pm 37$ & Full & 23 & 73 \\
\hline $97 / 01 / 17$ & 1256 & 1256 & $\mathrm{H} / \mathrm{L}$ & $1255: 04 \pm 17$ & Full & 22.5 & 68 \\
\hline $97 / 01 / 17$ & 1320 & 1318 & $\mathrm{H} / \mathrm{L}$ & $1319: 36 \pm 17$ & Full & 23.5 & 68 \\
\hline $97 / 01 / 21$ & 1428 & 1428 & $\mathrm{H} / \mathrm{L}$ & $1428: 07 \pm 18$ & Full & 22.5 & 66 \\
\hline $97 / 01 / 22$ & 1420 & 1420 & $\mathrm{H} / \mathrm{L}$ & $1417: 48 \pm 19$ & PSD & 22.5 & 68 \\
\hline $97 / 01 / 22$ & 1440 & 1441 & $\mathrm{H} / \mathrm{L}$ & $1440: 47 \pm 37$ & PSD & 23 & 68 \\
\hline $97 / 01 / 22$ & 1544 & 1544 & $\mathrm{H} / \mathrm{L}$ & $1539: 40 \pm 37$ & Full & 21 & 70 \\
\hline $97 / 01 / 27$ & 1526 & 1526 & $\mathrm{H} / \mathrm{L}$ & $1525: 48 \pm 18$ & Full & 22 & 69 \\
\hline $97 / 01 / 27$ & 1552 & 1551 & $\mathrm{H} / \mathrm{L}$ & $1551: 15 \pm 37$ & Full & 22.5 & 69 \\
\hline $97 / 02 / 02$ & 1321 & 1321 & $\mathrm{~L}$ & $1321: 19 \pm 18$ & Full & 23 & 68 \\
\hline $97 / 02 / 02$ & 1450 & 1450 & $\mathrm{~L}$ & $1449: 56 \pm 147$ & PSD & 1 & 69 \\
\hline $97 / 02 / 02$ & 1540 & 1541 & $\mathrm{~L}$ & $1533: 31 \pm 19$ & PSD & 23 & 68 \\
\hline $97 / 02 / 07$ & 1300 & 1259 & $\mathrm{~L}$ & $1259: 09 \pm 18$ & PSD & 0.5 & 69 \\
\hline
\end{tabular}

${ }^{a} \mathrm{H} / \mathrm{L}$ indicates AKR breakup (high-altitude and low-altitude AKR), and L indicates low-altitude AKR without high-altitude AKR. PSD and full represent auroral pseudosubstorm and full substorm, respectively.

${ }^{\mathrm{b}}$ Date format is year/month/day. 


\begin{tabular}{|c|c|}
\hline AKR Type & Auroral Type \\
\hline $\begin{array}{l}\text { AKR Beakup } \\
\text { (13 events) }\end{array}$ & $\begin{array}{c}\text { full-substorm } \\
\left|\begin{array}{l}\mid \\
\mid \\
\mid\end{array}\right| 12 / 13\end{array}$ \\
\hline $\begin{array}{c}\text { Low-alt AKR } \\
\text { Without High-alti AKR } \\
\text { (7 events) }\end{array}$ & $\begin{array}{l}\text { ind } \\
\text { ipseudo-substrom } \\
\vdots \\
\vdots \\
1\end{array}$ \\
\hline
\end{tabular}

Figure 11. Correspondence between AKR and auroral types at substorm onset for typical 20 AKR events listed in Table 1.

confirm the individual substorm onsets for each auroral event, so that events surveyed were restricted to a limited local time band of 21-24 h MLT at Kakioka. Under these conditions, 13 AKR breakup events and seven low-altitude AKR events were obtained, as listed in Table 1 . The results showed that 12 of 13 AKR breakups were accompanied by full substorms and all of the seven low-altitude AKRs without high-altitude AKR were accompanied by pseudosubstorms (see Figure 11). This confirms that what distinguishes a full substorm from a pseudosubstorm is the breakout of high-altitude acceleration in the M-I coupling region.

\subsection{Role of Low-Altitude Acceleration at Full Substorm}

[31] The previous case studies have suggested that highaltitude acceleration at full substorm is induced during the course of development of low-altitude acceleration. To confirm this suggestion, superposed epoch analysis on the development of both high-altitude and low-altitude acceleration was carried out. Data from two months of AKR observation by Polar/PWI (from 1 December 1996 to 31 January 1997) and Pi2 observation by the SAMNET magnetic network were used to sample isolated full substorms, and 11 full substorms were obtained. The results are given in Figure 12, where Figures 12a and $12 \mathrm{~b}$ correspond to the superposed average-power profiles of high-altitude and low-altitude AKR, respectively. The epoch time $(t=0)$ was taken to be the time when high-altitude AKR showed a sudden rise of intensity. The red lines are the logarithmical mean value trace of the power profiles. It is shown from Figure 12 that the low-altitude acceleration began with a gradual increase about $4 \mathrm{~min}$, on average, prior to the breakout of high-altitude acceleration and occasionally began about $30 \mathrm{~s}$ prior to the breakout. These statistical results support the implication that the intensification of low-altitude acceleration is a necessary condition for highaltitude acceleration to break out and suggest that the breakout of high-altitude acceleration is ignited when lowaltitude acceleration reaches a certain threshold value, although the threshold value would not be constant but would vary from event to event. What determines the threshold to break out high-altitude acceleration in the M-I coupling region then becomes an important issue.

\section{Tail Plasma Dynamics and Field-Aligned Acceleration}

\subsection{Response of Field-Aligned Acceleration to Fast Plasma Flows in the Plasma Sheet}

[32] To investigate the relation of plasma sheet plasma dynamics to the M-I coupling region, in situ plasma flow observations were examined in connection with AKR. Clusters of short-duration high-speed ion flows (flow bursts) are often observed embedded in bursty bulk flow events in the central plasma sheet (CPS) [Baumjohann et al., 1989; Angelopoulos et al., 1992]. Figure 4 shows the correspondence between quiet time pseudosubstorms and plasma flow bursts in the plasma sheet. Figure $4 \mathrm{c}$ indicates the $V_{\perp} x$ observed by Geotail/LEP. The pseudosubstorm onsets at around 1046, 1054, and 1146 UT on 20 April 1997 were accompanied by isolated Earthward flow bursts. It should be noted that the start of each flow burst always occurred 1-2 min before the appearance of low-altitude acceleration.

[33] Figure 13b shows four intensifications of the fieldaligned acceleration found at around 0534, 0555, 0606, and 0626 UT from the remote observation of AKR by Geotail/ PWI on 4 May 1996. The intensifications were corresponded to ground irregular pulsations at Rabbit Lake (RABB) $(L=6.5$, midnight $(\mathrm{MLT})=725 \mathrm{UT})$, as shown by the arrows in Figure 13a. Figures 13c-13f are the in situ magnetic $\left(B_{X}, B_{Z}\right)$ electric $\left(E_{y \mathrm{SC}}\right)$ field and plasma flow velocity $V_{\perp} x$ from the Geotail/magnetic field (MGF), LEP observations in the near-Earth plasma sheet. The first pseudosubstorm around 0534 UT was not accompanied by

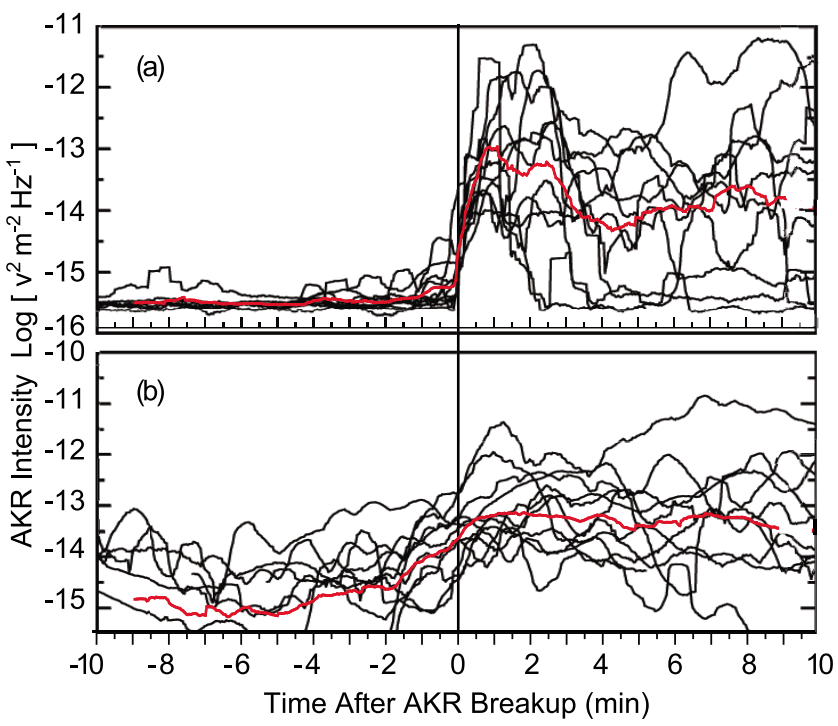

Figure 12. Superposed epoch analysis of 11 AKR evolutions, indicating fast rise of high-altitude AKR and gradual increase in low-altitude AKR at substorm onset. (a) Time profile of high-altitude AKR intensity. (b) Time profile of low-altitude AKR intensity. Epoch time $(t=0)$ is taken to be sudden rise of high-altitude AKR (AKR breakup). The red lines are the mean value trace of the power profiles. 


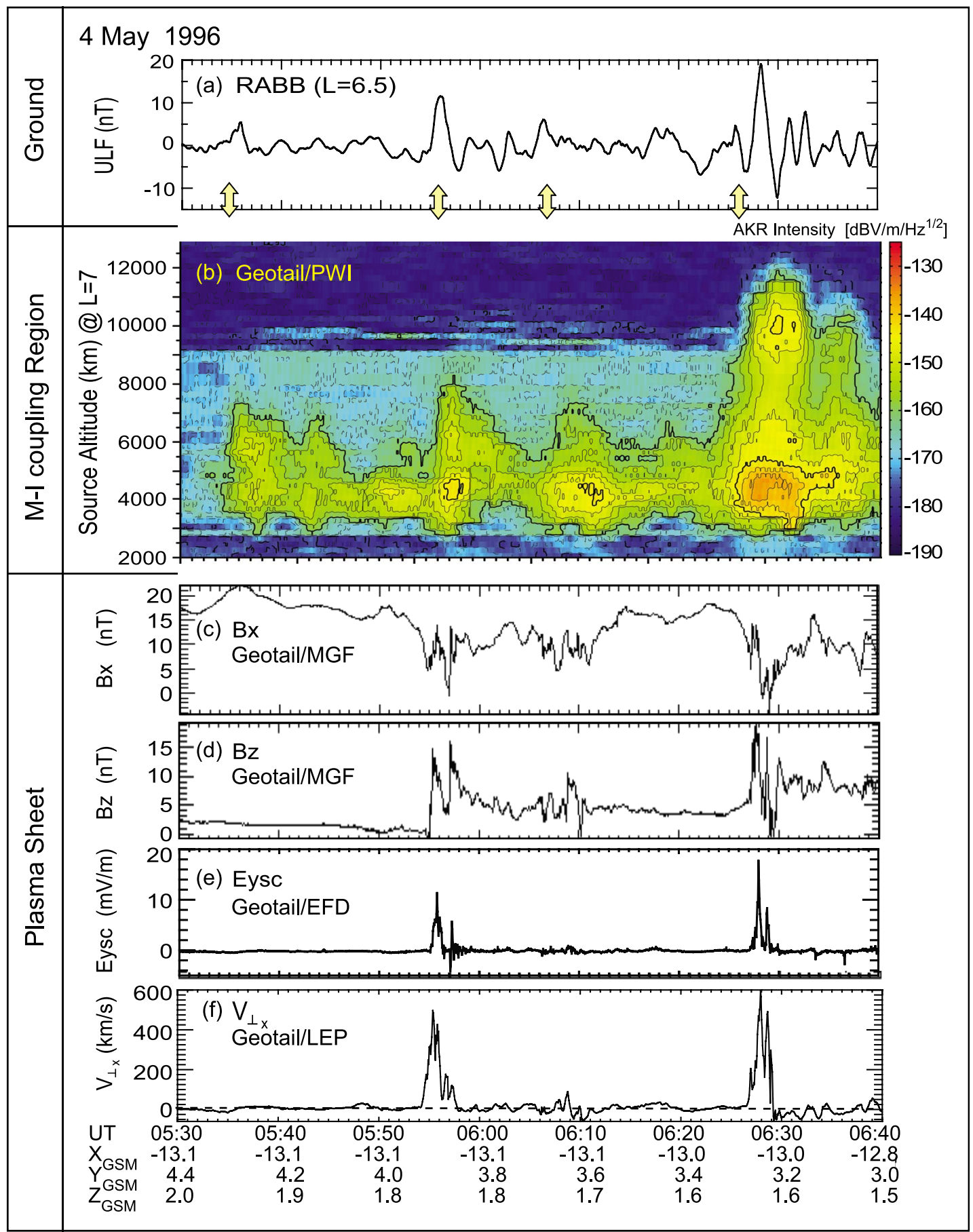

Figure 13. Field-aligned acceleration and tail plasma dynamics on 4 May 1996. (a) Magnetogram at RABB $(L=6.5)$. (b) An $a-t$ diagram of AKR source indicating the evolution of field-aligned acceleration. Three pseudosubstorms were observed at around 0534, 0555, and 0606 UT, and a full substorm was observed at around 0626 UT. Corresponding irregular pulsations are shown by the yellow arrows in Figure 13a. (c) Midtail magnetic field $B_{X}$ component and (d) $B_{Z}$ component from Geotail. (e) $Y$ component of electric field in satellite coordinates (Geotail observation). (f) $X$ component velocity of plasma flow perpendicular to local magnetic field in the midtail (Geotail observation).

any in situ field or plasma activities. Remote AKR enhancement without any in situ field or plasma disturbances can be attributed to the fact that (1) the flow burst was too small in the longitudinal direction [Angelopoulos et al., 1996; Nakamura et al., 2001b] to hit Geotail or (2) the flow burst ran so far from the Geotail location that only the resulting off-meridional AKR is observed at Geotail. The third pseudosubstorm around 0606 UT occurred with the magnetic field disturbances but without the electric field disturbances or particular flow bursts around the spacecraft. 
CPS $-15>X_{G S M}>-30$

\begin{tabular}{|c|c|c|}
\hline \multirow{2}{*}{$\begin{array}{l}\text { (i) Flow Bursts } \\
\text { Without AKR } \\
(34.7 \%)\end{array}$} & \multicolumn{2}{|c|}{ Flow Bursts With AKR (65.3\%) } \\
\hline & (ii) Low-alti AKR (0.66) & $\begin{array}{l}\text { (iii) AKR } \\
\text { Breakup (0.34) }\end{array}$ \\
\hline 20 & 60 & 80 \\
\hline
\end{tabular}

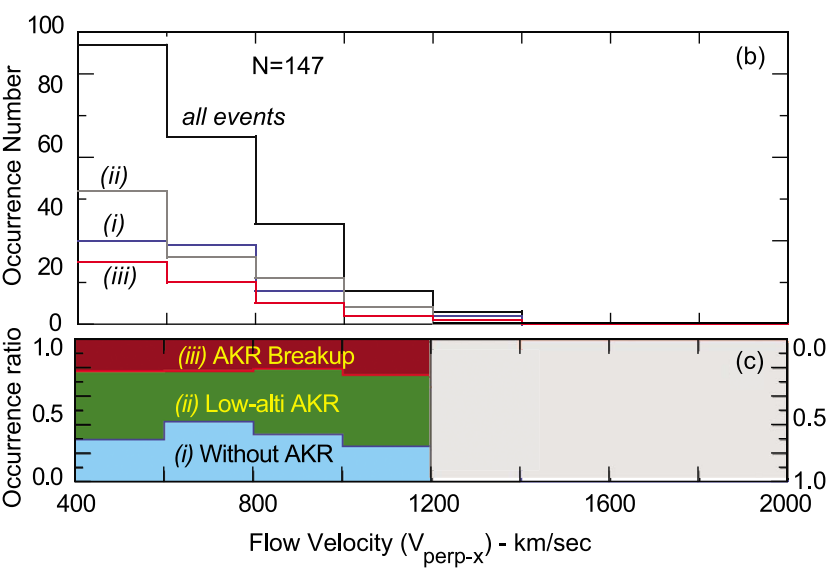

Figure 14. Statistical AKR response to plasma flow bursts in CPS. (a) Proportion of AKR association to flow bursts. AKR association is divided into three groups: (i) flow bursts without AKR, (ii) flow bursts with low-altitude AKR, and (iii) flow bursts with AKR breakup. (b) Dependence of AKR-related flow bursts on flow velocity. Four lines represent occurrences of all bursts (black line), flow bursts without AKR ((i), blue line), flow bursts with low-altitude AKR ((ii), green line), and flow bursts with AKR breakup ((iii), red line). (c) Occurrence ratio of flow bursts for groups (i), (ii), and (iii). Velocity range above $1200 \mathrm{~km} / \mathrm{s}$ is masked because of considerably low occurrences.

This is also considered to be a situation similar to the first one, although the trail of fast plasma flow would not have been so far from Geotail. When the second pseudosubstorm occurred at around 0555 UT, it was evident that the Earthward fast plasma flow burst ran through near the spacecraft with a velocity of $\sim 500 \mathrm{~km} / \mathrm{s}$, accompanying the strong dawn-dusk electric field of more than $6 \mathrm{mV} / \mathrm{m}$ and magnetic field disturbances which represent dipolarization. This indicates that the pseudosubstorm was caused by the typical flow burst event, which would be a manifestation of magnetic reconnection in the midtail.

[34] A full substorm occurred after 0620 UT, which can be identified from the breakout of high-altitude acceleration and large-amplitude Pi2 pulsation. This full substorm is composed of gradually increasing low-altitude acceleration that started at 0623 UT (first-step evolution), in an altitude range from 4000 to $6000 \mathrm{~km}$, and the subsequent explosive development of high-altitude acceleration (second-step evolution) in an altitude range from 8000 to $12,000 \mathrm{~km}$ at 0626 UT. The field and plasma data (Figures 13c-13f) around this full substorm exhibited typical substorm signatures in the plasma sheet [e.g., Nagai et al., 1998]: that is, dipolarization, an increased dawn-dusk electric field of more than $10 \mathrm{mV} / \mathrm{m}$, and an Earthward fast plasma flow with a velocity of about $600 \mathrm{~km} / \mathrm{s}$. It is noteworthy that both the pseudosubstorm at around 0555 UT and the full substorm at around 0626 UT followed considerably similar flow burst phenomena in the magnitude of their magnetic field and electric field variations and fast plasma flow velocities. This indicates that the scale of plasma dynamics in the plasma sheet does not make any difference between a full substorm and a pseudosubstorm. This is consistent with Ieda et al. [2001] and Ohtani et al. [2002b], and it repeats the question of what processes or conditions distinguish full substorms from pseudosubstorms.

\subsection{Statistical Relation Between Flow Bursts and Field-Aligned Acceleration}

[35] The response of acceleration in the M-I coupling region to Earthward plasma flow bursts in the plasma sheet was statistically investigated. Flow burst events were selected from the Geotail observations for the period from 23 February 1996 to 31 January 1997 under the following four criteria:

[36] 1. Geotail was located in the midtail CPS $\left(-15 R_{E} \leq\right.$ $X_{\mathrm{GSM}} \leq-30 R_{E}$, and plasma- $\beta \geq 1.0$ [Miyashita et al., 2000]).

[37] 2. The magnetic local time of the spacecraft was between $22 \mathrm{~h}$ and $01 \mathrm{~h}$.

[38] 3. The flow velocity $V_{\perp} x$ exceeded $400 \mathrm{~km} / \mathrm{s}$ as a working criterion [Baumjohann et al., 1990].

[39] 4. The duration was less than $10 \mathrm{~min}$.

[40] There were a total of 147 selected Earthward flow bursts. For all these events, simultaneous $a-t$ diagrams of AKR were examined to check the correspondence of fieldaligned acceleration with the flow bursts. The correspondence between them was decided when an enhancement or triggering of AKR occurred simultaneously with a flow burst within \pm 2 min.

[41] Figure 14 shows the occurrence characteristics of Earthward flow bursts in CPS in connection with AKR (field-aligned acceleration). Figure 14a shows the occurrence rates for AKR association, indicating that about $65 \%$ of flow bursts were related to the activation or triggering of AKR and the remaining $35 \%$ had no connection with AKR. It also shows that about two thirds of AKR-related flow bursts corresponded to low-altitude AKR (low-altitude acceleration), and the remaining one third corresponded to AKR breakup (high-altitude acceleration). This means that only $22 \%$ of flow bursts relate to the trigger of full substorm and $43 \%$ of flow bursts relate to pseudosubstorm. Figure $14 \mathrm{~b}$ shows the flow velocity distribution binned every 200 $\mathrm{km} / \mathrm{s}$ from 400 to $2000 \mathrm{~km} / \mathrm{s}$ for (i) flow bursts without AKR (hereafter, class-i, blue line), (ii) flow bursts with low-altitude AKR (hereafter, class-ii, green line), (iii) flow bursts with AKR breakup (hereafter, class-iii, red line), and all flow bursts that were detected (black line). The number of flow bursts with velocities above $1200 \mathrm{~km} / \mathrm{s}$ suddenly decreases, as is consistent with Ohtani et al. [2002b]. The occurrence ratio with respect to the flow velocity is shown in Figure $14 \mathrm{c}$, where velocity bins greater than $1200 \mathrm{~km} / \mathrm{s}$ are masked because the number of events observed above a velocity of $1200 \mathrm{~km} / \mathrm{s}$ is not sufficient to estimate the occurrence probability. The occurrence ratio of class $-\mathrm{i}$, class-ii, and class-iii flow bursts showed no dependence on the flow velocity, suggesting that the magnitude of Earthward flow velocity is not a significant factor to generate field-aligned acceleration in the M-I coupling region. 

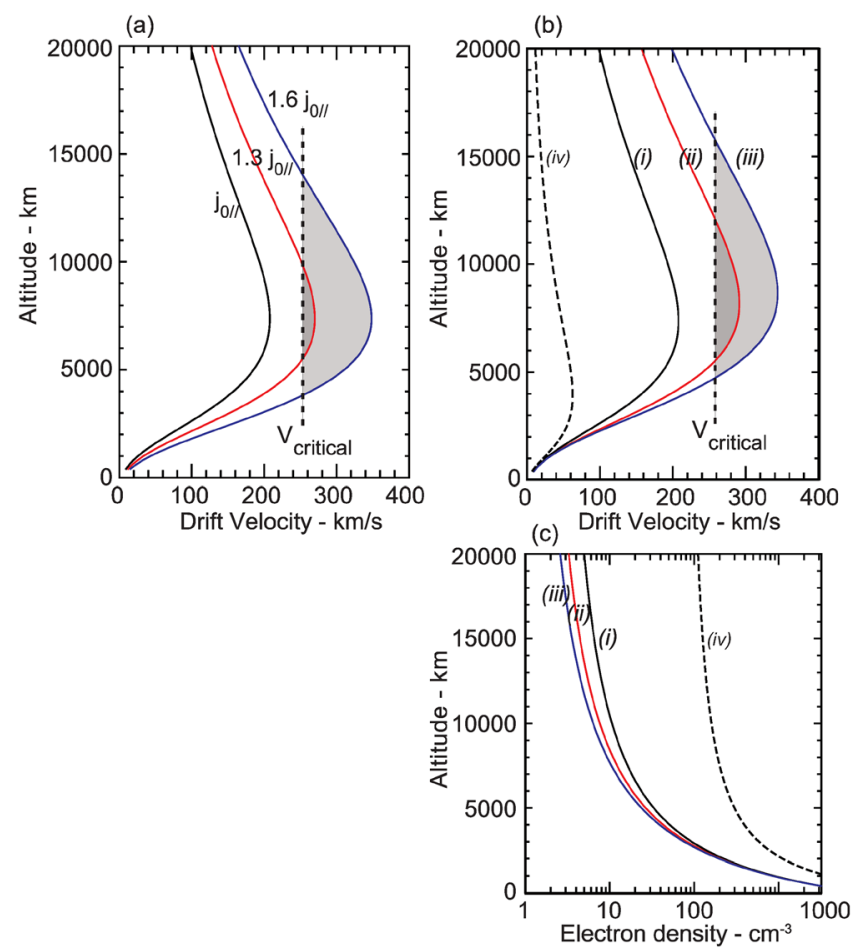

Figure 15. Drift velocity of FAC-carrying electrons. (a) Altitude profile of electron drift velocity with respect to three current intensities: $j_{0 / /}, 1.3 j_{0 / /}$, and $1.6 j_{0 / /}$. Vertical dashed line indicates imaginary critical velocity $V_{C}$ for current/current-driven instability. Background electron density is based on profile (i) of Figure 15c (auroral plasma cavity). (b) Solid curves, altitude profiles of electron drift velocity in auroral plasma cavity with respect to background electron density profiles of (i), (ii), and (iii) in Figure 15c; dotted curve, altitude profile of electron drift velocity in off-cavity latitude with respect to background electron density profile of (iv) in Figure 15c. (c) Background electron density profiles in auroral cavity (MLAT $=68^{\circ}$ ) (curves (i), (ii), and (iii)) and off-cavity latitude (MLAT $=60^{\circ}$ ) curve (iv) based on the Akebono observations.

\section{Summary and Discussion}

[42] The substantial evidence that substorm onset is characterized by the vertical evolution of field-aligned acceleration in the M-I coupling region [Morioka et al., 2009] has been reinforced with detailed examinations in this paper. Enhancement of low-altitude acceleration appears first and then, $30 \mathrm{~s}$ to a few minutes later, high-altitude acceleration breaks out explosively as if it is induced by the former. This two-step vertical evolution of auroral fieldaligned acceleration is consistent with the earlier descriptions of horizontal auroral expansion by Akasofu [1964] (stage I (sudden brightening) and stage II (breakup) of expansion phase), Kaneda and Yamamoto [1991] (initial brightening and flaring up), and Lyons et al. [2002] (intensity change in "breakup arc" from monotonic to dramatic increase).

[43] The generation of auroral field-aligned acceleration has been discussed in terms of two categories. The first is the formation of a large-scale quasistatic potential difference in the auroral upper ionosphere, which is self-consistently built up due to mixing magnetospheric plasma with ionospheric plasma in the M-I coupling region [e.g., Chiu and Schulz, 1978; Borovsky, 1993, and references therein]. The second is the transient and local formation of a potential drop in the M-I coupling region due to some plasma instabilities and/or kinetic Alfvén waves [e.g., Borovsky, 1993, and references therein]. The former and latter categories would correspond to two types of acceleration in this paper, respectively: low-altitude acceleration formed at an altitude of $4000-5000 \mathrm{~km}$, and the breakout of transient high-altitude acceleration built up within a few 10 s of seconds at an altitude of $6000-12,000 \mathrm{~km}$.

\subsection{Low-Altitude Acceleration and FAC}

[44] The observation clearly demonstrated that the activation of low-altitude acceleration without the breakout of high-altitude acceleration leads to a pseudosubstorm and low-altitude acceleration followed by sudden high-altitude acceleration causes a full substorm. The activation process for the low-altitude acceleration, however, does not show apparent differences between the pseudosubstorm and the initial stage of the full substorm. On the other hand, highaltitude acceleration seems to be induced during the course of increasing magnitude of the low-altitude acceleration at a full substorm (see Figure 12). This implies that low-altitude acceleration is a necessary condition for the ignition of highaltitude acceleration.

[45] Morioka et al. [2008, 2009] demonstrated that the enhancement of low-altitude acceleration accompanies the gradual increase in upward FAC at the auroral latitude. This suggests that the FAC that originated in the plasma sheet controls the low-altitude potential structure following the Knight relation [Knight, 1973; Lyons, 1981], where the motive force of FAC is in the plasma dynamics in the plasma sheet [Haerendel, 1992]. The field-aligned potential structure is regulated through the coupling process between magnetospheric and ionospheric plasmas. Chiu and Schulz [1978] estimated the distribution of the field-aligned electrostatic field through a magnetic mirror process and showed that the distribution has a maximum height of around 3000 $\mathrm{km}$ above the auroral ionosphere. This height is somewhat consistent with the low-altitude acceleration derived from AKR observations in this study, suggesting that low-altitude acceleration is generated by mechanisms proposed by Chiu and Schulz [1978].

\subsection{Current/Current-Driven Instability in Upper M-I Coupling Region}

[46] The drift velocity of FAC-carrying electrons plays a crucial role in current/current-driven instabilities in the M-I coupling region. When the gradually increasing FAC reaches some critical value, it is expected to induce certain current/current-driven instability in the M-I coupling region. Note that the height distribution of electron drift velocity has a broad maximum above the upper ionosphere of 1-1.5 $R_{E}$ [Mozer et al., 1977; Morooka and Mukai, 2003]. Figure 15a plots the estimated height distribution of the drift velocity in the auroral plasma cavity for three cases of FAC intensity $\left(j_{/ /}\right.$ ${ }_{0}, 1.3 j_{/ / 0}$, and $\left.1.6 j_{/ / 0}\right)$, where $j_{/ / 0}$ is the current density at the ionospheric altitude and is taken to be $3.0 \mu \mathrm{A} / \mathrm{m}^{2}$ in the present case. The background electron density ( $N-h$ profile) 
(a)

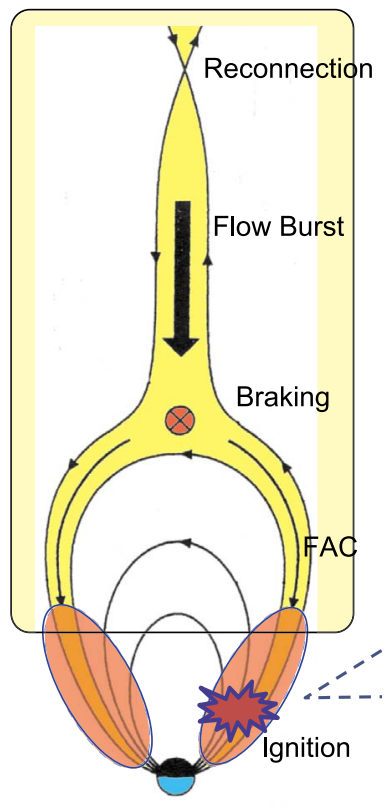

(b)

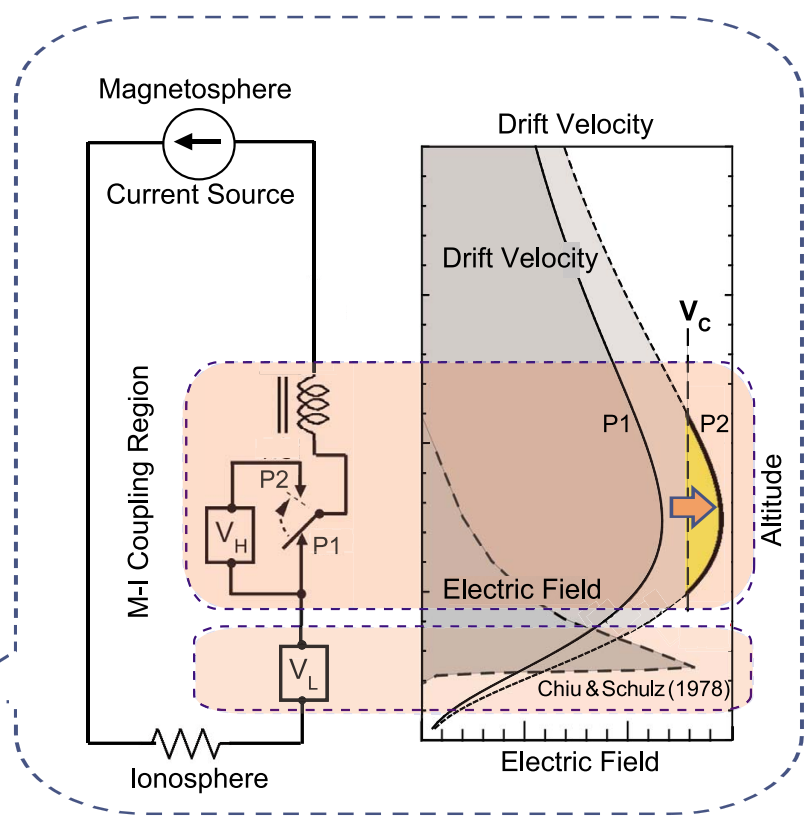

Figure 16. Schematic picture of proposed substorm process. (a) Magnetosphere-ionosphere coupling. (b) Electric circuit model for the M-I coupling region. When electromagnetic relay operates, current flow route changes from throughpoint 1 (P1) to throughpoint 2 (P2). (c) Drift velocity profiles responsible for high-altitude acceleration (upper curves) and field-aligned electric field distribution derived from magnetic mirror process [Chiu and Schulz, 1978] responsible for low-altitude acceleration (lower dashed curve). Drift velocity curves of P1 and P2 represent the states at prebreakup and breakup, respectively.

is based on the empirical model derived from the Akebono observations [Sato, 1998; Morioka et al., 2005] (see $\mathrm{N}$ $h$ profile (i) in Figure $15 \mathrm{c}$ ). It is evident that the current carrying electrons have a peak drift velocity at an altitude of $5000-10,000 \mathrm{~km}$, and the drift velocity changes sensitively to the change in current density. The altitude distribution of the drift velocity in the auroral plasma cavity is also sensitive to the $N-h$ profile. The drift velocity profiles (i), (ii), and (iii) in Figure 15b, corresponding to the $N$-h profiles of (i), (ii), and (iii) (at magnetic latitude $(\mathrm{MLAT})=68^{\circ}$ ) in Figure $15 \mathrm{c}$, reveal that the drift velocity in the auroral cavity increases its maximum velocity and peak altitude, being sensitive to a slight electron density decrease in the upper ionosphere. Drift velocity distribution and corresponding $N$ $h$ profile in off-cavity latitude (MLAT $=60^{\circ}$ ) are shown by the dotted curve (iv) in Figures 15b and 15c, for reference. These characteristics of the drift velocity strongly support the idea that, when increasing FAC exceeds the critical velocity of $V_{C}$ (vertical dotted line in Figures $15 \mathrm{a}$ and $15 \mathrm{~b}$ ), the current triggers current or current-driven instability in the upper M-I coupling region, leading to double-layer or anomalous resistivity [e.g., Main et al., 2006; Pottelette and Treumann, 2005; Ergun et al., 2004; Kindel and Kennel, 1971]. The buildup of high-altitude acceleration can be attributed to this kind of instability in the M-I coupling region.

\subsection{What Divides Substorms Into Pseudosubstorms and Full Substorms?}

[47] The time difference between the first (low-altitude) and second (high-altitude) evolutions ranges from less than
1 min to a few minutes. This time difference could correspond to the time interval until the FAC increases to a certain level to induce high-altitude instability. However, the "certain level to induce instability," which can be roughly represented by the magnitude of low-altitude acceleration, should change from event to event, as seen in Figure 12. This suggests that current/current-driven instability is triggered, depending not only on FAC intensity but also on the background plasma environment that controls a level to induce the instability in the M-I coupling region.

[48] From these considerations, we propose that the answer to what divides the substorms into pseudosubstorms and full substorms lies in the M-I coupling system itself. A conceptualization of this is illustrated in Figure 16. Figure $16 \mathrm{~b}$ analogically illustrates an FAC circuit where the current generated in the magnetosphere is fed to a part in the M-I coupling region. The part can be compared to an electromagnetic relay, and the drain current from the relay is connected to a break contact point (normally closed: P1) of the relay. The current then flows through the low-altitude potential $\left(V_{L}\right)$ into the ionosphere. This situation corresponds to the enhanced low-altitude acceleration (pseudosubstorm/initial brightening before the breakup). When the increasing FAC exceeds the operational current of the relay (critical drift velocity for instability $V_{C}$ ) and operates the relay (outbreak of instability), the current flows through an albeit contact point (normally open: P2) of the relay and generates the high-altitude potential structure of $V_{H}$ (current or current-driven instability). Here, the operational current intensity of the relay is determined by the number of turns in relay coil, and the number of turns in the relay coil would 


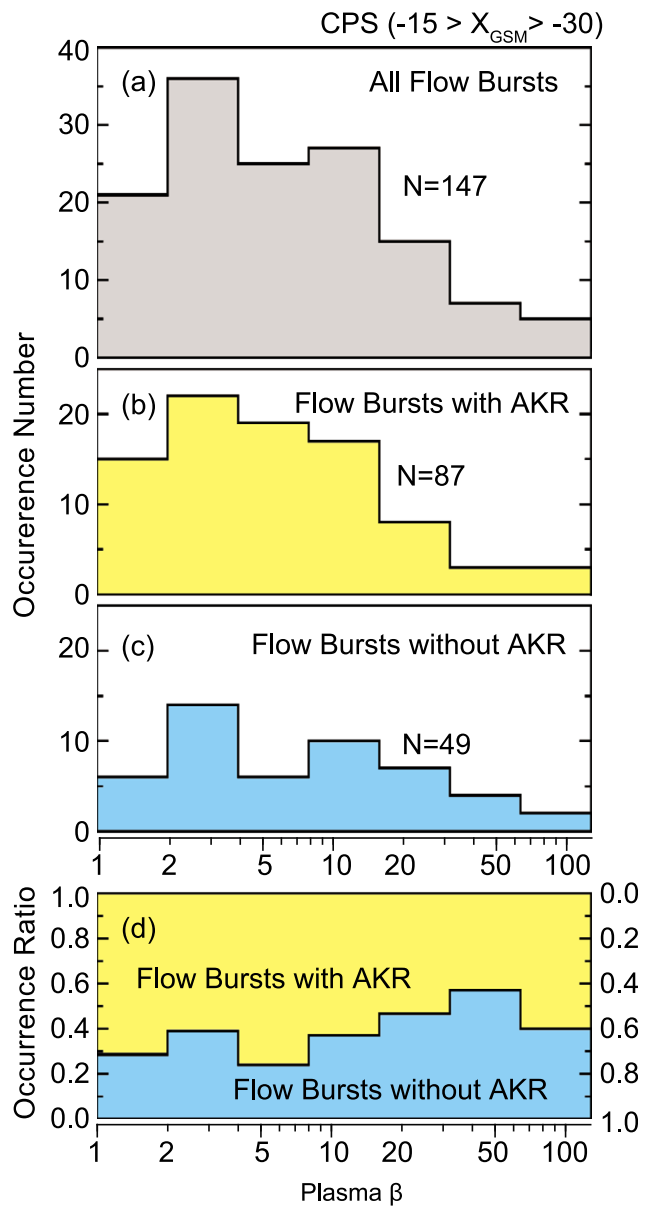

Figure 17. Dependence of flow bursts in the plasma sheet on plasma $\beta$. (a) Occurrences of all of the detected flow bursts with respect to plasma $\beta$. (b) Occurrences of flow bursts with AKR with respect to plasma $\beta$. (c) Occurrences of flow bursts without AKR with respect to plasma $\beta$. (d) Occurrence ratio of flow bursts with and without AKR with respect to plasma $\beta$.

analogically correspond to the background plasma parameters in the M-I coupling region. Thus, the critical current for instability can vary from event to event, as indicated in Figure 12, depending on the background plasma environment of the M-I coupling region.

\subsection{Is Inertial Alfvén Wave Effective to the Two-Step Acceleration?}

[49] Particle energization by inertial Alfvén waves in the auroral upper ionosphere is also a candidate for onset acceleration. Observations [e.g., Gary et al., 1998; Stasiewicz et al., 2000; Mende et al., 2003] indicated that Alfvén waves accelerate auroral superthermal electrons almost consistent with theories and simulations [e.g., Hasegawa, 1976; Lysak and Lotko, 1996; Chaston et al., 2003]. Chaston et al. [2007] reported large parallel electric fields above the auroral oval which may occur in double layers driven by Alfvén wave current. Wygant et al. [2002] and Janhunen et al. [2004] showed Alfvén acceleration process at high altitude $\left(4-5 R_{E}\right)$ in substorms. The relation of these Alfvén wave acceleration processes to the substorm onset is, however, not yet well known in both observational and theoretical sides. There are two major constraints to apply inertial Alfvén wave to onset time two-step acceleration presented in this paper. The first is that Alfvén acceleration should be effective at two distinct altitudes (4000-5000 km and 6000-12,000 km). Especially, the evidence that observed high-altitude acceleration region is above the ionospheric Alfvén resonator is crucial for the Alfvén acceleration. The second is the Alfvén acceleration is required to energize electrons up to kiloelectron volt energies to excite breakup arc and cause cosmic noise absorption at substorm onset. Because these constraints are apart from onset acceleration, the Alfvén acceleration process is put aside in the following discussion.

\subsection{Two-Component Pi2 Pulsation at Substorm Onset}

[50] The ULF wave analysis conclusively confirmed the earlier findings [Kadokura et al., 2002; Morioka et al., 2009; Kataoka et al., 2009] that Pi2 pulsation around substorm onset is composed of two components: the first (prebreakup Pi) associated with the appearance of lowaltitude acceleration and auroral initial brightening with longer periods of $50-100 \mathrm{~s}$ and the second (breakup Pi) associated with the breakout of high-altitude acceleration and auroral breakup with shorter periods of less than $50 \mathrm{~s}$. It is interesting to note that the prebreakup Pi embedded in the ground $\mathrm{Pi} 2$ demonstrated somewhat similar characteristics with ballooning-mode ULF waves in the inner plasma sheet [Cheng and Lui, 1998; Saito et al., 2008] in the period range and appearance in the early phase of substorm onset. If they are identical, this implies that the enhanced FAC generated in the inner plasma sheet accompanies magnetic perturbation, which can propagate to auroral altitude along the field line and cause wavy auroral modulation [Liang et al., 2008] and/or local arc undulation [Rae et al., 2009], as seen at $t 1$ in Figure 9. The breakup Pi with shorter periods is inferred to be a lower-frequency component of Pil pulsation induced at auroral breakup [Milling et al., 2008; Murphy et al., 2009]. Our observations also found that they propagate down to middle and low latitudes. The relation of magnetospheric Alfvén waves to onset pulsations on the ground is of recent interest in the energization of auroral electrons at substorm onset [Voronkov, 2005; Keiling et al., 2008].

\subsection{Plasma Flow Bursts and Field-Aligned Acceleration}

[51] Fairfield et al. [1999] investigated the relation between Earthward flow bursts in the inner magnetosphere and auroral substorms and showed that AKR intensification usually accompanied flow bursts in close time coincidence. The association of AKR with plasma flow bursts was statistically examined in this paper to investigate the response of the M-I coupling region to magnetospheric dynamics at substorm onset. Important evidence disclosed from the statistical study is that about $35 \%$ of flow bursts do not affect the intensification or activation of field-aligned acceleration; that is, they have no effect on pseudosubstorms and full substorms (see Figure 14a). The flows in this group do not have particular velocity characteristics compared with those of flow bursts with AKR, as seen in Figure 14c. However, further study has indicated that the flow bursts without AKR have contrastive plasma $\beta$ characteristics to the flow bursts 
with AKR. Figure 17a indicates the occurrence characteristics of all of the detected flow bursts with respect to the in situ plasma $\beta$ (plasma $\beta$ of the flow burst), and Figure $17 \mathrm{~b}$ indicates those of flow bursts with AKR. These plots demonstrate that the majority of the flow bursts were composed of lower- $\beta$ plasma. In contrast, flow bursts without AKR (Figure 17c) showed a relatively flat distribution with respect to plasma $\beta$. This tendency is clearly seen in Figure 17d which shows that flow bursts with AKR are rather apt to occur when plasma $\beta$ is low, and vice versa. This evidence indicates that flow bursts composed of lower- $\beta$ plasma, which would correspond to a magnetic-fluxrich plasma bubble [Schödel et al., 2001], are phenomenologically more effective in activating the M-I coupling region and, consequently, substorm onset. Although more detailed analysis is necessary, one possible explanation is that the magnetic field pileup of low- $\beta$ flow bursts drives FAC at the braking zone in the near-Earth plasma sheet.

[52] The other important evidence obtained from the statistical study of flow bursts is that about $42 \%$ of flow bursts cause low-altitude field-aligned acceleration (pseudosubstorm), and only $22 \%$ of flow bursts relate to high-altitude acceleration (full substorm). It should be noted that neither of these substorm-associated flow bursts exhibit distinct dependence on flow velocity, as shown in Figure 14c. This again confirms that the magnitude of flow velocity, which is considered to be a rough measure of flow braking at the near-Earth plasma sheet, is not always an essential factor in triggering full substorms, being consistent with the case study by Ohtani et al. [2002a], and consequently concludes that arrival of flow burst generated through the magnetic reconnection is not a sufficient condition to drive a full substorm, being consistent with Ieda et al. [2001].

[53] It would be natural to consider from these observations that the low- $\beta$ flow bursts that arrived at the inner plasma sheet do participate in generating low-altitude acceleration but are not concerned with the ignition of highaltitude acceleration. The ignition of high-altitude acceleration would be a matter of the M-I coupling region; that is, the background plasma parameters of the M-I coupling region control the ignition, as discussed in subsection 7.3. This harmonizes with the suggestion by Ohtani et al. [2002a] that there is an additional (or alternative) condition that suffices to develop an initial brightening into a full substorm.

\subsection{Scenario for the Two-Step Evolution at Substorm Onset}

[54] Here, we propose a scenario for substorm onset that comprehends the processes taking place in the plasma sheet and M-I coupling region. Schematic illustration of this has been shown in Figure 16a. A flow burst is generated through the magnetic reconnection in the midtail and moves Earthward transporting magnetic flux [e.g., Baumjohann et al., 1990; Shiokawa et al., 1998a; Runov et al., 2009]. The pileup of magnetic field carried by the flow burst results in braking of the flow burst near the Earth, which causes the inertial current. This pileup of magnetic field is more effective when the flow burst is composed of low- $\beta$ plasma. The inertial current diverges to the FAC during the initial phase of the substorm [Haerendel, 1992; Shiokawa et al., $1998 \mathrm{~b}$, and the current regulates the field-aligned poten- tial ( $V_{L}$ in Figure 16b) following the Knight relation (the low-altitude electric field estimated by Chiu and Schulz [1978] is shown in Figure 16c). This corresponds to the low-altitude acceleration presented in this paper, which initiates initial brightening or pseudobreakup.

[55] The increasing FAC during initial brightening then leads to sudden current/current-driven instability in the M-I coupling region when the current exceeds a critical level (Figures 16b and 16c): that is, the breakout of high-altitude acceleration ( $V_{H}$ in Figure 16b) which causes violent electron precipitation and the resulting auroral breakup. This situation is represented by the status change from P1 to P2 in Figure 16b. Tail current disruption and the following abrupt enforcement of the substorm current wedge [ $\mathrm{Lui}$, 1996] would start, at this time, being induced by strong rushing FAC from the ionosphere and would expand both latitudinally and longitudinally as the instability region expands in the M-I coupling region.

[56] The condition to develop initial brightening/pseudobreakup into a breakup/full substorm (analogous to the operation of the "ionospheric relay circuit" in Figure 16b) is determined by both the FAC intensity in the magnetosphere (supplied current intensity to the circuit) and the critical electron velocity $V_{\mathrm{C}}$ in the ionosphere (operational current determined by the number of turns in the relay coil).

[57] The suggestion that current carrier electrons of the plasma sheet control the buildup of acceleration in the M-I coupling region accords with Morioka et al. [2003] and Seki et al. [2005], who showed the disappearance of the fieldaligned potential drop during a storm due to sufficient plasma sheet electrons to drive FAC without any acceleration.

\section{Conclusions}

[58] The two-step evolution of field-aligned acceleration was shown in connection with auroral substorm onset on the basis of AKR source dynamics. Our investigations revealed that the auroral acceleration process basically consists of two steps. The first is the appearance/intensification of lowaltitude acceleration at an altitude of 4000-5000 km that induces initial brightening. The second step is the breakout of high-altitude field-aligned acceleration (6000-12,000 $\mathrm{km}$ ) above preexisting low-altitude acceleration, which results in violent auroral breakup and poleward expansion. Low-altitude acceleration which is not followed by the breakout of high-altitude acceleration (one-step evolution) is a pseudosubstorm.

[59] Plasma-flow bursts in the CPS were investigated in connection with the evolution of field-aligned acceleration in the M-I coupling region. About $65 \%$ of the flow bursts were related to field-aligned acceleration in the M-I coupling region, and one third of them developed to full substorm, while the magnitude of the flow velocity did not necessarily divide between the pseudosubstorm and full substorm. It is also shown that flow bursts composed of higher- $\beta$ plasma made it somewhat harder to affect the M-I coupling region.

[60] We proposed a substorm onset scenario where an Earthward flow burst generated by midtail reconnection caused the first-step evolution of substorms (low-altitude acceleration), and the subsequent instability driven by 
enhanced FAC in the M-I coupling region ignited substorm breakup.

[61] Acknowledgments. We are grateful to K. Shiokawa, A. Ieda and S. Machida for their useful comments and discussions. We also wish to thank the Geotail team of PWI (Principal Investigator: H. Kojima), MGF (Principal Investigator: T. Nagai), EFD (Principal Investigator: H. Hayakawa), and LEP (Principal Investigator: Y. Saito). We thank I. R. Mann for data from the CARISMA magnetometer array; CARISMA is operated and deployed by the University of Alberta and funded by the Canadian Space Agency. Data were provided through the Canadian Space Science Data Portal. We acknowledge D. DeLapp for processing the LANL energetic particle data at the Los Alamos National Laboratory. We would like to thank the SAMNET team for the magnetometer data; SAMNET is operated by Lancaster University and is funded by STFC. The $1 \mathrm{~s}$ resolution geomagnetic data were observed at the Kakioka Magnetic Observatory of the Japan Meteorological Agency and provided through the WDC-2 for Geomagnetism at Kyoto University, Japan.

[62] Robert Lysak thanks the reviewers for their assistance in evaluating this paper.

\section{References}

Aikio, A. T., V. A. Sergeev, M. A. Shukhtina, L. I. Vagina, V. Angelopoulos, and G. D. Reeves (1999), Characteristics of pseudobreakups and substorms observed in the ionosphere, at the geosynchronous orbit, and in the midtail, J. Geophys. Res., 104(A6), 12,263-12,287, doi:10.1029/ 1999JA900118.

Akasofu, S.-I. (1964), The development of the auroral substorm, Planet Space Sci., 12, 273-282.

Angelopoulos, V., W. Baumjohann, C. Kennel, F. Coroniti, M. Kivelson, R. Pellat, R. Walker, H. Lühr, and G. Paschmann (1992), Bursty bulk flows in the inner central plasma sheet, J. Geophys. Res., 97(A4), 4027-4039, doi:10.1029/91JA02701.

Angelopoulos, V., et al. (1996), Multipoint analysis of a bursty bulk flow event on April 11, 1985, J. Geophys. Res., 101(A3), 4967-4989, doi:10.1029/95JA02722.

Angelopoulos, V., et al. (2008), Tail reconnection triggering substorm onset, Science, 321, 931-935.

Arnoldy, R. L., P. B. Lewis, and P. O. Isaacson (1974), Field-aligned auroral electron fluxes, J. Geophys. Res., 79(28), 4208-4221, doi:10.1029/ JA079i028p04208.

Baker, D. N., T. I. Pulkkinen, V. Angelopoulos, W. Baumjohann, and R. L. McPherron (1996), Neutral line model of substorms: Past results and present view, J. Geophys. Res., 101(A6), 12,975-13,010, doi:10.1029/ 95JA03753.

Baumjohann, W., G. Paschmann, and C. A. Cattell (1989), Average plasma properties in the central plasma sheet, J. Geophys. Res., 94(A6), 65976606, doi:10.1029/JA094iA06p06597.

Baumjohann, W., G. Paschmann, and H. Luhr (1990), Characteristics of high-speed ion flows in the plasma sheet, J. Geophys. Res., 95(A4) 3801-3809, doi:10.1029/JA095iA04p03801.

Borovsky, J. E. (1993), Auroral arc thicknesses as predicted by various theories, J. Geophys. Res., 98(A4), 6101-6128, doi:10.1029/92JA02242.

Chaston, C. C., J. W. Bonnell, C. W. Carlson, and J. P. McFadden (2003), Properties of small-scale Alfvén waves and accelerated electrons from FAST, J. Geophys. Res., 108(A4), 8003, doi:10.1029/2002JA009420.

Chaston, C. C., A. J. Hull, J. W. Bonnell, C. W. Carlson, R. E. Ergun, R. J. Strangeway, and J. P. McFadden (2007), Large parallel electric field, current, and density cavities in dispersive Alfvén waves above the aurora, J. Geophys. Res., 112, A05215, doi:10.1029/2006JA012007.

Cheng, C. Z., and A. T. Y. Lui (1998), Kinetic ballooning instability for substorm onset and current disruption observed by AMPTE/CCE, Geophys. Res. Lett., 25(21), 4091-4094, doi:10.1029/1998GL900093.

Chiu, Y. T., and M. Schulz (1978), Self-consistent particle and parallel electrostatic field distributions in the magnetospheric-ionospheric auroral region, J. Geophys. Res., 83(A2), 629-642, doi:10.1029/ JA083iA02p00629.

de Feraudy, H., J. Hanasz, R. Schreiber, G. Parks, M. Brittnacher, S. Perraut, J. A. Sauvaud, F. Lefeuvre, and M. M. Mogilevsky (2001), AKR bursts and substorm field line excitation, Phys. Chem. Earth C, 26, 151-159.

Donovan, E. F., T. S. Trondsen, L. L. Cogger, and B. J. Jackel (2003), Allsky imaging within the Canadian CANOPUS and NORSTAR projects, Sodankyla Geophys. Obs. Publ., 92, 109-112.

Donovan, E., et al. (2006), The azimuthal evolution of the substorm expansion phase onset aurora, in Proceedings of the ICS-8, edited by
M. Syrjäsuo and E. F. Donovan, pp. 55-60, Univ. of Calgary, Calgary, AB, Canada.

Ergun, R. E., et al. (1998), FAST satellite wave observations in the AKR source region, Geophys. Res. Lett., 25(12), 2061-2064, doi:10.1029/ 98GL00570.

Ergun, R. E., L. Anderson, D. S. Main, and Y.-J. Su (2002), Parallel electric fields in the upward current region of the aurora: Indirect and direct observations, Phys. Plasmas, 9, 3685-3694.

Ergun, R. E., L. Andersson, D. Main, Y.-J. Su, D. L. Newman, M. V. Goldman, C. W. Carlson, A. J. Hull, J. P. McFadden, and F. S. Mozer (2004), Auroral particle acceleration by strong double layers: The upward current region, J. Geophys. Res., 109, A12220, doi:10.1029/ 2004JA010545

Erickson, G. M., N. C. Maynard, W. J. Burke, G. R. Wilson, and M. A. Heinemann (2000), Electromagnetics of substorm onsets in the near-geosynchronous plasma sheet, J. Geophys. Res., 105(A11), 25,265-25,290, doi:10.1029/1999JA000424.

Evans, D. S. (1974), Precipitating electron fluxes formed by a magnetic field-aligned potential difference, J. Geophys. Res., 79(19), 2853 2858, doi:10.1029/JA079i019p02853.

Fairfield, D. H., et al. (1999), Earthward flow bursts in the inner magnetotail and their relation to auroral brightening, AKR intensifications, geosynchronous particle injections and magnetic activity, J. Geophys. Res., 104(A1), 355-370, doi:10.1029/98JA02661.

Gary, J. B., L. Zanetti, B. Anderson, T. Potemra, J. Clemmons, J. Winningham, and J. Sharber (1998), Identification of auroral oval boundaries from in situ magnetic field measurements, J. Geophys. Res., 103(A3), 4187-4197, doi:10.1029/97JA02395.

Gurnett, D. A., et al. (1995), The polar plasma wave instrument, Space Sci. Rev., 71, 597-622.

Haerendel, G. (1992), Disruption, ballooning or auroral avalanche: On the cause of substorms, Proceedings of the International Conference on Substorms (ICS-1), pp. 417-420, Eur. Space Agency, Paris.

Hanasz, J., H. de Feraudy, R. Schreiber, G. Parks, M. Brittnacher, M. M. Mogilevsky, and T. V. Romantsova (2001), Wideband bursts of auroral kilometric radiation and their association with UV auroral bulges, J. Geophys. Res., 106(A3), 3859-3871, doi:10.1029/2000JA900098.

Hasegawa, A. (1976), Particle acceleration by MHD surface wave and formation of aurora, J. Geophys. Res., 81(28), 5083-5090, doi:10.1029/ JA081i028p05083.

Ieda, A., D. H. Fairfield, T. Mukai, Y. Saito, S. Kokubun, K. Liou, C.-I. Meng, G. K. Parks, and M. J. Brittnacher (2001), Plasmoid ejection and auroral brightenings, J. Geophys. Res., 106(A3), 3845-3857, doi:10.1029/1999JA000451.

Janhunen, P., A. Ollson, J. Hanasz, C. T. Russell, H. Laakso, and J. C. Samson (2004), Different Alfvén wave acceleration processes of electrons in substorms at $\sim 4-5 R_{E}$ and 2-3 $R_{E}$ radial distance, Ann. Geophys, 22, 2213-2227

Kadokura, A., A.-S. Yukimatu, M. Ejiri, T. Oguti, M. Pinnock, and P. R. Sutcliffe (2002), Detailed analysis of a substorm event on 6 and 7 June 1989: 2. Stepwise auroral bulge evolution during expansion phase, $J$. Geophys. Res., 107(A12), 1480, doi:10.1029/2001JA009129.

Kaiser, M. L., and J. K. Alexander (1977), Relationship between auroral substorms and the occurrence of terrestrial kilometric radiation, J. Geophys. Res., 82(32), 5238-5286, doi:10.1029/JA082i032p05283.

Kaneda, E., and T. Yamamoto (1991), Auroral substorms observed by UVimager on Akebono, in Magnetospheric Substorms, Geophys. Monogr Ser., vol. 64, edited by J. R. Kan et al., pp. 235-240, AGU, Washington, D. C.

Kasaba, Y., H. Hayakawa, K. Ishisaka, T. Okada, A. Matsuoka, T. Mukai, and Y. Takei (2006), Evaluation of DC electric field measurement by the double probe system abroad the Geotail spacecraft, Adv. Space Res., 37, 604-609.

Kataoka, R., Y. Miyoshi, and A. Morioka (2009), Hilbert-Huang Transform of geomagnetic pulsations at auroral expansion onset, J. Geophys. Res., 114, A09202, doi:10.1029/2009JA014214.

Keiling, A., et al. (2008), Multiple intensification inside the auroral bulge and their association with plasma sheet activities, J. Geophys. Res., 113, A12216, doi:10.1029/2008JA013383.

Kindel, J. M., and C. F. Kennel (1971), Topside current instabilities, J. Geophys. Res., 76(13), 3055-3078, doi:10.1029/JA076i013p03055.

Knight, S. (1973), Parallel electric fields, Planet. Space Sci., 21, 741-750.

Kokubun, S., T. Yamamoto, M. H. Acuna, K. Hayashi, K. Shiokawa, and H. Kawano (1994), The GEOTAIL magnetic field experiment, J. Geomagn. Geoelectr., 46, 7-21.

Koskinen, H. E. J., R. E. Lopez, R. J. Pellinen, T. I. Pulkkinen, D. N. Baker, and T. Bosinger (1993), Pseudobreakup and substorm growth phase in the ionosphere and magnetosphere, J. Geophys. Res., 98(A4), 5801-5813, doi:10.1029/92JA02374. 
Kullen, A., and T. Karlsson (2004), On the relation between solar wind, pseudobreakups, and substorms, J. Geophys. Res., 109, A12218, doi:10.1029/2004JA010488.

Liang, J., E. F. Donovan, W. W. Liu, B. Jackel, M. Syrjasuo, S. B. Mende, H. U. Frey, V. Angelopoulos, and M. Connors (2008), Intensification of preexisting auroral arc at substorm expansion phase onset: Wave-like disruption during the first tens of seconds, Geophys. Res. Lett., 35 , L17S19, doi:10.1029/2008GL033666.

Liou, K., C.-I. Meng, A. T. Lui, and P. T. Newell (2000), Auroral kilometric radiation at substorm onset, J. Geophys. Res., 105(A11), 25,325-25,331, doi:10.1029/2000JA000038.

Louarn, P., A. Roux, H. de Féraudy, and D. Le Quéau (1990), Trapped electrons as a free energy source for the auroral kilometric radiation, $J$. Geophys. Res., 95(A5), 5983-5995, doi:10.1029/JA095iA05p05983.

Lui, A. T. Y. (1996), Current disruption in the Earth's magnetosphere: Observations and models, J. Geophys. Res., 101(A6), 13,067-13,088, doi:10.1029/96JA00079.

Lui, A. T. Y., R. E. Lopez, B. J. Anderson, K. Takahashi, L. J. Zanetti, R. W. McEntire, T. A. Potemra, D. M. Klumpar, E. M. Greene, and R. Strangeway (1992), Current disruption in the near-Earth neutral sheet region, J. Geophys. Res., 97(A2), 1461-1480, doi:10.1029/ 91JA02401.

Lui, A. T. Y., et al. (2008), Determination of the substorm initiation region from a major conjunction interval of THEMIS satellites, J. Geophys. Res., 113, A00C04, doi:10.1029/2008JA013424.

Lyons, L. R. (1981), The field-aligned current versus electric potential relation and auroral electrodynamics, in Physics of Auroral Arc Formation, Geophys. Monogr. Ser., vol. 25, edited by S.-I. Akasofu and J. R. Kan, pp. 252-259, AGU, Washington, D. C.

Lyons, L. R., I. O. Voronkov, E. F. Donovan, and E. Zesta (2002), Relation of substorm breakup arc to other growth-phase auroral arcs, J. Geophys. Res., 107(A11), 1390, doi:10.1029/2002JA009317.

Lysak, R. L., and W. Lotko (1996), On the kinetic dispersion relation for shear Alfvén waves, J. Geophys. Res., 101(A3), 5085-5094, doi:10.1029/95JA03712.

Main, D. S., D. L. Newman, and R. E. Ergun (2006), Double layers and ion phase-space holes in the auroral upward-current region, Phys. Rev. Lett. 97, 185001, doi:10.1103/PhysRevLett.97.185001.

Mann, I. R., et al. (2008), The Upgraded CARISMA magnetometer array in the THEMIS Era, Space Sci. Rev., 141, 413-451.

Matsumoto, H., I. Nagano, R. R. Anderson, H. Kojima, K. Hashimoto, M. Tsutsui, T. Okada, I. Kimura, Y. Omura, and M. Okada (1994), Plasma wave observations with GEOTAIL spacecraft, J. Geomagn. Geoelectr., 46, 59-95.

McFadden, J. P., C. W. Carlson, and R. E. Ergun (1999a), Microstructure of the auroral acceleration region as observed by FAST, J. Geophys. Res., 104(A7), 14,453-14,480, doi:10.1029/1998JA900167.

McFadden, J. P., C. W. Carlson, R. E. Ergun, D. M. Klumpar, and E. Moebius (1999b), Ion and electron characteristics in auroral density cavities associated with ion beams: No evidence for cold ionospheric plasma, J. Geophys. Res., 104(A7), 14,671-14,682, doi:10.1029/ 1999JA900035.

McPherron, R. L. (1991), Physical processes producing magnetospheric substorms and magnetic storms, in Geomagnetism, vol. 4, edited by J. A. Jacobs, pp. 593-739, Academic, San Diego, Calif.

Mende, S. B., C. W. Carlson, H. U. Frey, T. J. Immel, and J.-C. Gérard (2003), IMAGE FUV and in situ FAST particle observations of substorm auroae, J. Geophys. Res., 108(A4), 8010, doi:10.1029/2002JA009413.

Milling, D. K., I. J. Rae, I. R. Mann, K. R. Murphy, A. Kale, C. T. Russell, V. Angelopoulos, and S. Mende (2008), Ionospheric localisation and expansion of long-period Pil pulsations at substorm onset, Geophys. Res. Lett., 35, L17S20, doi:10.1029/2008GL033672.

Miyashita, Y., S. Machida, T. Mukai, Y. Saito, K. Tsuruda, H. Hayakawa, and P. Sutcliffe (2000), A statistical study of variations in the near and middistant magnetotail associated with substorm onsets: GEOTAIL observations, J. Geophys. Res., 105(A7), 15,913-15,930, doi:10.1029/ 1999JA000392.

Mizera, P. F., and J. F. Fennell (1977), Signatures of electric fields from high and low altitude particles distributions, Geophys. Res. Lett., 4(8), 311-314, doi:10.1029/GL004i008p00311.

Morioka, A., H. Oya, and S. Miyatake (1981), Terrestrial kilometric radiation observed by satellite Jikiken (Exos-B), J. Geomagn. Geoelecter., 33, 37-62.

Morioka, A., et al. (2003), AKR disappearance during magnetic storms, $J$. Geophys. Res., 108(A6), 1226, doi:10.1029/2002JA009796.

Morioka, A., Y. Miyoshi, F. Tsuchiya, H. Misawa, A. Kumamoto, H. Oya H. Matsumoto, K. Hashimoto, and T. Mukai (2005), Auroral kilometric radiation activity during magnetically quiet periods, J. Geophys. Res., 110, A11223, doi:10.1029/2005JA011204.
Morioka, A., Y. Miyoshi, F. Tsuchiya, H. Misawa, T. Sakanoi, K. Yumoto, R. R. Anderson, J. D. Menietti, and E. F. Donovan (2007), Dual structure of auroral acceleration regions at substorm onsets as derived from AKR spectra, J. Geophys. Res., 112, A06245, doi:10.1029/2006JA012186.

Morioka, A., et al. (2008), AKR breakup and auroral particle acceleration at substorm onset, J. Geophys. Res., 113, A09213, doi:10.1029/ 2008JA013322.

Morioka, A., Y. Miyoshi, F. Tsuchiya, H. Misawa, K. Yumoto, G. K. Parks, R. R. Anderson, J. D. Menietti, and F. Honary (2009), Vertical evolution of auroral acceleration at substorm onset, Ann. Geophys., 27, $525-535$.

Morooka, M., and T. Mukai (2003), Density as a controlling factor for seasonal and latitudinal variations of the auroral particle acceleration region, J. Geophys. Res., 108(A7), 1306, doi:10.1029/2002JA009786.

Mozer, F. S., and A. Hull (2001), Origin and geometry of upward electric fields in the auroral acceleration region, J. Geophys. Res., 106(A4) 5763-5778, doi:10.1029/2000JA900117.

Mozer, F. S., and C. A. Kletzing (1998), Direct observation of large, quasistatic, parallel electric fields in the auroral acceleration region, Geophys. Res. Lett., 25(10), 1629-1632, doi:10.1029/98GL00849.

Mozer, F. S., C. W. Carlson, M. K. Hudson, R. B. Torbert, B. Paraday, J. Yateau, and M. C. Kelley (1977), Observations of paired electrostatic shocks in the polar magnetosphere, Phys. Rev. Lett., 38, 292-295.

Mukai, T., et al. (1994), The Low Energy Particle (LEP) experiment onboard the Geotail satellite, J. Geomagn. Geoelectr., 46, 669-692.

Murphy, K. R., I. J. Rae, I. R. Mann, D. K. Milling, C. E. J. Watt, L. Ozeke, H. U. Frey, V. Angelopoulos, and C. T. Russell (2009), Wavelet-based ULF wave diagnosis of substorm expansion phase onset, J. Geophys. Res., 114, A00C16, doi:10.1029/2008JA013548.

Nagai, T., M. Fujimoto, Y. Saito, S. Machida, T. Terasawa, R. Nakamura T. Yamamoto, T. Mukai, A. Nishida, and S. Kokubun (1998), Structure and dynamics of magnetic reconnection for substorm onsets with Geotail observations, J. Geophys. Res., 103(A3), 4419-4440, doi:10.1029/ 97JA02190.

Nakamura, R., D. N. Baker, T. Yamamoto, R. D. Belian, E. A. Bering III, J. R. Benbrook, and J. R. Theall (1994), Particle and field signatures during pseudobreakup and major expansion onset, J. Geophys. Res., 99(A12), 207-221, doi:10.1029/93JA02207.

Nakamura, W. Baumjohann, M. Brittnacher, V. A. Sergeev, M. Kubyshkina, T. Mukai, and K. Liou (2001a), Flow bursts and auroral activations: Onse timing and foot point location, J. Geophys. Res., 106(A6), 10,777-10,789, doi:10.1029/2000JA000249.

Nakamura, W. Baumjohann, R. Schödel, M. Brittnacher, V. A. Sergeev, M. Kubyshkina, T. Mukai, and K. Liou (2001b), Earthward flow bursts, auroral streamers, and small expansions, J. Geophys. Res., 106(A6), 10,791-10,802, doi:10.1029/2000JA000306.

Ohtani, S., et al. (1993), A multisatellite study of a pseudo-substorm onset in the near-Earth magnetotail, J. Geophys. Res., 98(A11), 19,35519,367, doi:10.1029/93JA01421.

Ohtani, S., R. Yamaguchi, H. Kawano, F. Creutzberg, J. B. Sigwarth, L. A. Frank, and T. Mukai (2002a), Does the braking of the fast plasma flow trigger a substorm?: A study of the August 14, 1996, event, Geophys. Res. Lett., 29(15), 1721, doi:10.1029/2001GL013785.

Ohtani, S., R. Yamaguchi, M. Nosé, H. H. Kawano, M. Engebretson, and K. Yumoto (2002b), Quiet time magnetotail dynamics and their implications for the substorm trigger, J. Geophys. Res., 107(A2), 1030, doi:10.1029/2001JA000116.

Olsson, A., P. Janhunen, J. Hanasz, M. Mogilevsky, S. Perraut, and J. D. Menietti (2004), Observational study of generation conditions of substorm-associated low-frequency AKR emissions, Ann. Geophys., 22, 3571-3582.

Partamies, N., O. Amm, K. Kauristie, T. I. Pulkkinen, and E. Tanskanen (2003), A pseudo-breakup observation: Localized current wedge across the postmidnight auroral oval, J. Geophys. Res., 108(A1), 1020, doi:10.1029/2002JA009276.

Pottelette, R., and R. A. Treumann (2005), Electron holes in the auroral upward current region, Geophys. Res. Lett., 32, L12104, doi:10.1029/ 2005GL022547.

Pottelette, R., R. A. Treumann, and M. Berthomier (2001), Auroral plasma turbulence and cause of auroral kilometric radiation fine structure, J. Geophys. Res., 106(A5), 8465-8476, doi:10.1029/2000JA000098.

Pritchett, P. L., R. J. Strangeway, C. W. Carlson, R. E. Ergun, J. P. McFadden, and G. T. Delory (1999), Free energy sources and frequency bandwidth for the auroral kilometric radiation, J. Geophys. Res., 104(A5), 10,317-10,326, doi:10.1029/1998JA900179.

Pritchett, P. L., R. J. Strangeway, R. E. Ergun, and C. W. Carlson (2002), Generation and propagation of cyclotron maser emissions in the finite auroral kilometric radiation source cavity, J. Geophys. Res., 107(A12), 1437, doi:10.1029/2002JA009403. 
Rae, I. J., et al. (2009), Timing and localization of ionospheric signatures associated with substorm expansion phase onset, J. Geophys. Res., 114, A00C09, doi:10.1029/2008JA013559.

Runov, A., V. Angelopoulos, M. I. Sitnov, V. A. Sergeev, J. Bonnell, J. P. McFadden, D. Larson, K.-H. Glassmeier, and U. Auster (2009), THEMIS observations of an Earthward-propagating dipolarization front, Geophys. Res. Lett., 36, L14106, doi:10.1029/2009GL038980.

Saito, M. H., et al. (2008), Ballooning mode waves prior to substorm-associated dipolarizations: Geotail observations, Geophys. Res. Lett., 35 , L07103, doi:10.1029/2008GL033269.

Sato, Y. (1998), A study on electron density distributions at high latitude, M.S. thesis, Tohoku Univ., Sendai, Japan.

Schödel, R., R. Nakamura, and W. Baumjohann (2001), Rapid flux transport and plasma sheet reconfiguration, J. Geophys. Res., 106(A5), 83818390, doi:10.1029/2000JA900159.

Seki, T., et al. (2005), Auroral kilometric radiation and magnetosphereionosphere coupling process during magnetic storms, J. Geophys. Res., 110, A05206, doi:10.1029/2004JA010961.

Sergeev, V. A., V. Angelopoulos, D. G. Mitchell, and C. T. Russell (1995), In situ observations of magnetotail reconnection prior to the onset of a small substorm, J. Geophys. Res., 100(A10), 19,121-19,133, doi:10.1029/95JA01471.

Shelley, E. G., R. D. Sharp, and R. G. Johnson (1976), Satellite observations of an ionospheric acceleration mechanism, Geophys. Res. Lett., 3 (11), 654-656, doi:10.1029/GL003i011p00654.

Shiokawa, K., et al. (1998a), High-speed ion flow, substorm current wedge, and multiple Pi 2 pulsations, J. Geophys. Res., 103(A3), 4491-4507, doi:10.1029/97JA01680.

Shiokawa, K., G. Haerendel, and W. Baumjohann (1998b), Azimutha pressure gradient as driving force of substorm currents, Geophys. Res. Lett., 25(7), 959-962.

Stasiewicz, K., et al. (2000), Small scale Alfvénic structure in the aurora, Space Sci. Rev., 92, 423-533.

Strangeway, R. J., R. E. Ergun, C. W. Carlson, J. P. McFadden, G. T. Delory, and P. L. Pritchett (2001), Accelerated electrons as the source of auroral kilometric radiation, Phys. Chem. Earth C, 26, 145-149.

Torr, M. R., et al. (1995), A far ultraviolet image for the International Solar-Terrestrial Physics’ Mission, Space Sci. Rev., 71, 329-383.
Tsuruda, K. et al. (1994), Electric field measurements on the Geotail satellite, J. Geomagn. Geoelectr., 46, 693-711.

Voronkov, I. O. (2005), Near-Earth breakup triggered by Earthward traveling burst flow, Geophys. Res. Lett., 32, L13107, doi:10.1029/ 2005GL022983.

Wygant, J. R. et al. (2002), Evidence for kinetic Alfvén waves and parallel electron energization at 4-6 RE altitudes in the plasma sheet boundary layer, J. Geophys. Res., 107(A8), 1201, doi:10.1029/2001JA900113.

Yumoto, K., and $210^{\circ} \mathrm{MN}$ Magnetic Observation Group (1996), The $210^{\circ}$ magnetic meridian network project, J. Geomagn. Geoelctr., 48, 1297-1309.

E. Donovan, Department of Physics and Astronomy, University of Calgary, Calgary, AB T2N 1N4, Canada.

F. Honary, Department of Communication Systems, Lancaster University, Lancaster LA1 4WA, UK.

A. Kadokura, National Institute of Polar Research, Tokyo 190-8518, Japan

Y. Kasaba, Geophysical Institute, Tohoku University, Sendai 980-8578, Japan.

R. Kataoka, Interactive Research Center, Tokyo Institute of Technology, Tokyo 152-8550, Japan.

K. Liou, Johns Hopkins University Applied Physics Laboratory, Laurel, MD 20723, USA

D. J. Menietti, Department of Physics and Astronomy, University of Iowa, Iowa City, IA 52242, USA.

H. Misawa, A. Morioka, and F. Tsuchiya, Planetary Plasma and Atmospheric Research Center, Tohoku University, Sendai 980-8587, Japan. (morioka@pparc.geophys.tohoku.ac.jp)

Y. Miyashita and Y. Miyoshi, Solar-Terrestrial Environment Laboratory, Nagoya University, Nagoya 464-8601, Japan.

T. Mukai, Japan Aerospace Exploration Agency, Tokyo 182-8522, Japan.

G. Parks, Space Sciences Laboratory, University of California, Berkeley, CA 94720, USA.

K. Yumoto, Space Environment Research Center, Kyushu University, Fukuoka 812-8581, Japan. 